\title{
Retrospective Prediction of Macroseismic Intensities Using Strong Ground Motion Simulation: The Case of the 1978 Thessaloniki (Greece) Earthquake (M6.5)
}

\author{
NIKOLAOS THEODULIDIS ${ }^{1, *}$, ZAFEIRIA ROUMELIOTI $^{2}$, \\ ARETI PANOU ${ }^{1,2}$, ALEXANDROS SAVVAIDIS ${ }^{1}$, ANASTASIA \\ KIRATZI $^{2}$, VASSILIOS GRIGORIADIS ${ }^{3}$, PETROS DIMITRIU ${ }^{1}$ \\ and THEODOROS CHATZIGOGOS ${ }^{4}$ \\ ${ }^{1}$ Institute of Engineering Seismology and Earthquake Engineering (ITSAK), Thessaloniki, \\ Greece; ${ }^{2}$ Division of Geophysics, Department of Geology, Aristotle University of Thessaloniki, \\ 54124 Thessaloniki, Greece; ${ }^{3}$ Division of Geodesy and Surveying, Department of Rural and \\ Surveying Engineering, Aristotle University of Thessaloniki, 54124 Thessaloniki, Greece; \\ ${ }^{4}$ Laboratory of Soil Mechanics and Foundations, Division of Geotechnical Engineering, \\ Department of Civil Engineering, Aristotle University of Thessaloniki, 54124 Thessaloniki, \\ Greece \\ *Corresponding author: Tel: +302310476081, Fax: +30-2310-476085, E-mail: ntheo@itsak.gr
}

Received 11 May 2005; accepted 26 January 2006 / Published online: 1 April 2006

\begin{abstract}
The densely populated city of Thessaloniki (Northern Greece) is situated in the vicinity of active seismic faults, capable of producing moderate to strong earthquakes. The city has been severely affected by such events several times during the last 15 centuries. The most recent event occurred on 20 June 1978 (M6.5) in the Mygdonian graben, with an epicentral distance of about $30 \mathrm{~km}$, causing extended damage in the city, with macroseismic intensities between MSK V+ and VIII+. The majority of buildings affected by the earthquake were of reinforced-concrete typology, typical to many southern European metropolitan areas. The source properties of the normal-faulting causative event and the source-to-city propagation path are well known from previous studies. The soil structure under the metropolitan area of Thessaloniki is assigned NEHRP categories B, C, D on the basis of geotechnical and geologic information and single-station ambient-noise measurements. A finite source model and various rupture scenarios of the June 1978 earthquake are used to perform forward stochastic modeling of strong ground motion in terms of peak ground and spectral acceleration. Rock motion is assessed under the city and it is transferred to the surface in accordance with the respective soil category. A GIS tool is employed to compare the estimated strong-motion parameters with the observed detailed damage pattern induced by the 1978 earthquake. For selected natural periods, a satisfactory correlation is established between macroseismic intensity and peak ground and spectral acceleration, thus encouraging the application of stochastic modeling for generating realistic ground-shaking scenarios in metropolitan areas.
\end{abstract}

Key words: ambient noise, macroseismic intensity, seismic hazard, stochastic simulation, Thessaloniki 1978 earthquake 


\section{Introduction}

The city of Thessaloniki in Northern Greece, the second largest city in terms of population after the capital Athens, was the first urban area in Greece to be hit by a strong earthquake in modern times. The earthquake occurred on 20 June 1978 (20:03:21 GMT; M6.5; 40.73 $\left.{ }^{\circ} \mathrm{N}, 23.25^{\circ} \mathrm{E}\right)$ at an epicentral distance of $30 \mathrm{~km}$ to the east of Thessaloniki and demonstrated the vulnerability of a modern city. An eight-storey reinforcedconcrete building collapsed in the city center, causing 37 deaths out of 47 in total from the main shock. Overall, 4000 buildings suffered serious, 13000 intermediate and 49000 only slight damage. No loss of life in the villages near the epicenter was reported. Figure 1 shows the location of the city and the causative fault.

Systematic processing of damage distribution within the city of Thessaloniki has been attempted in the past relying on statistical treatment of loss assessment in terms of repairing cost (Penelis et al., 1985; Kappos et al., 1991) as well as by means of questionnaires (Leventakis, 2003). Seismic-intensity data derived on the basis of questionnaires are rather easy to obtain and can be used for advanced studies of seismic-source properties, propagation-path characteristics and site effects, as well as for comparative studies involving other seismological data (Ohta et al., 1985).

In this paper we use stochastic finite-source modeling (Beresnev and Atkinson, 1997, 1998) to simulate ground motion (peak-ground and spectral acceleration) and retrospectively predict the spatial distribution of the damage (macroseismic intensity) in the urban area of Thessaloniki. First, ground motion on rock (assumed here to be soil category B after NEHRP) is assessed under the city. Surface ground motions are then calculated at various locations by applying amplification factors corresponding to the respective soil categories. A GIS tool is finally employed to facilitate the comparison of the estimated ground-motion parameters with the observed detailed damage pattern, in term of macroseismic intensity, due to the June 20, 1978 earthquake.

\section{Stochastic approach for ground motion simulation}

There is a plethora of approaches to ground motion simulation, including pure deterministic (e.g. Hartzell, 1978; Irikura, 1983), stochastic (Boore 2003 and references therein) and hybrid ones (e.g. Kamae et al., 1998; Pitarka et al., 2000, 2002; Pulido and Kubo, 2004; Pulido et al., 2004). Among the diverse available methods for strong ground motion simulation we chose to use the stochastic method for finite-faults as suggested by Beresnev and Atkinson (1997). The specific method was chosen for the simplicity of its input parameters and its proven applicability to strong ground 


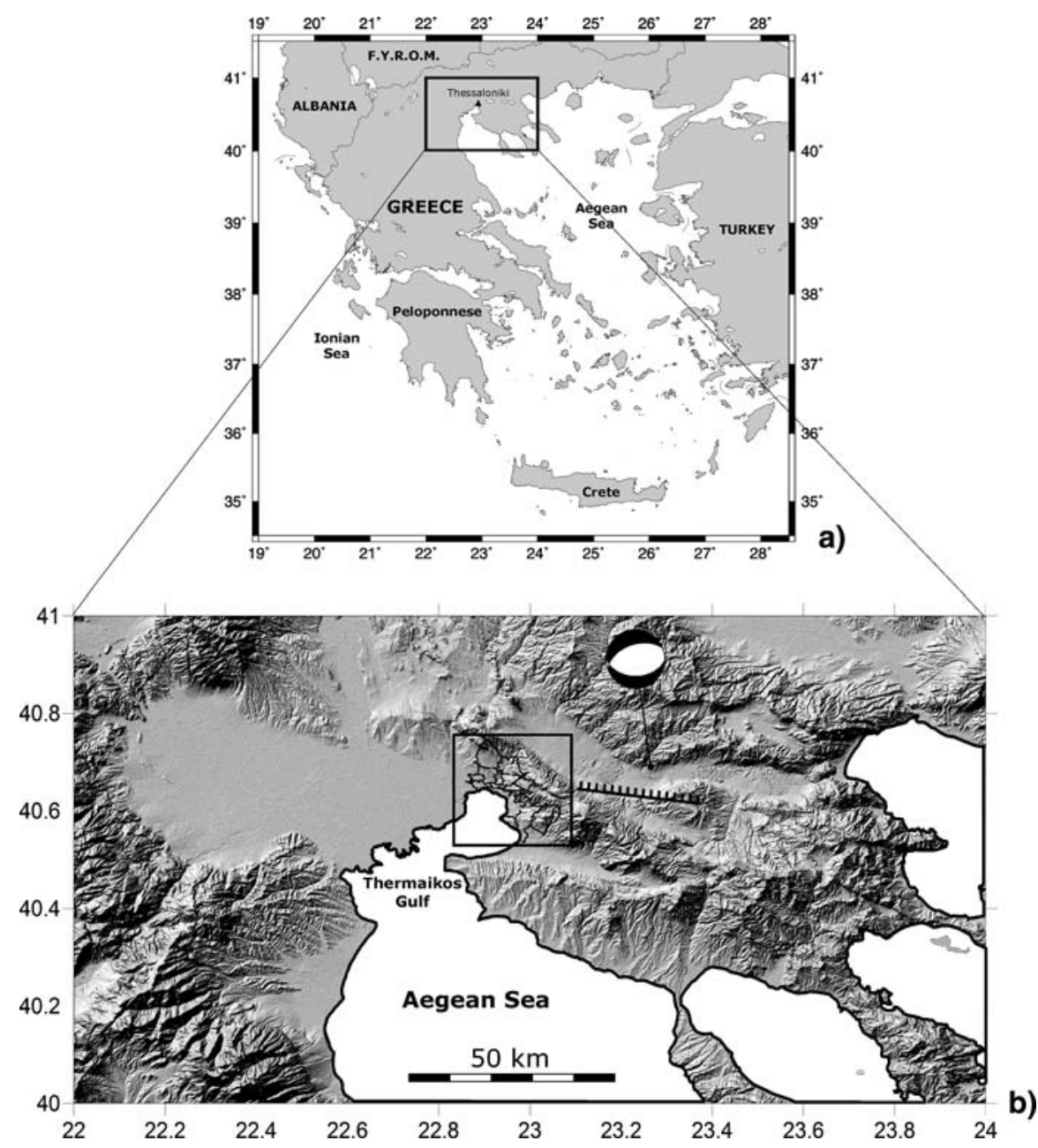

Figure 1. (a) Map showing the location of the study area; (b) the fault of the 20 June 1978 earthquake with heavy hatched lines on the downthrown side, the focal mechanism of the main shock and the metropolitan area of Thessaloniki.

motion simulation (usually throughout the frequency range of engineering interest: $0.1-20 \mathrm{~Hz}$ ) in diverse seismotectonic environments (e.g. Berardi et al., 2000; Beresnev and Atkinson, 2001a,b; Castro et al., 2001; Hough et al., 2002; Iglesias et al., 2002; Erdik and Durukal, 2003; Roumelioti and Beresnev, 2003; Singh et al., 2003; Roumelioti et al., 2004; Castro and Ruiz-Cruz, 2005). For a detailed discussion about the advantages of using the stochastic method for finite-faults even in comparison with deterministic and hybrid methods the reader is referred to the work of Motazedian and Atkinson (2005). 
In the stochastic modeling technique (Beresnev and Atkinson 1997, 1998), the Fourier amplitude spectrum of a seismic signal, $A(\omega)$, is represented as the product of a spectrum, $S(\omega)$, that accounts for the effects of the seismic source and several other filtering functions that represent the effects of the propagation path and the recording site. If the receiver installation site can be characterized as hard rock, the shear-wave acceleration spectrum is given by:

$$
A(\omega)=2 \omega^{2} \times S(\omega) \times P(\omega) e^{-\omega R / 2 Q \beta}
$$

where $\omega$ is the angular frequency, $R$ is the hypocentral distance, $Q$ is the quality factor introduced to account for the regional inelastic attenuation, and $\beta$ is the shear-wave velocity. The filtering function $P(\omega)$ is used for the commonly observed spectral cutoff above a certain frequency $\omega_{\mathrm{m}}$. This phenomenon is either attributed to the processes that take place at the source during the occurrence of an earthquake (Papageorgiou and Aki, 1983; Papageorgiou, 1988) or to the high-frequency attenuation by the nearsurface weathered layers (Hanks, 1982; Anderson and Hough, 1984; Beresnev and Atkinson, 1997; Theodulidis and Bard, 1998). Here $P(\omega)$ has the form of the fourth-order Butterworth filter:

$$
P(\omega)=\left[1+\left(\omega / \omega_{\mathrm{m}}\right)^{8}\right]^{-1 / 2}
$$

The function $S(\omega)$ is calculated as the product of a certain deterministic function (usually the $\omega^{-2}$ model), which defines the average shape and amplitude of the spectrum, and a stochastic function (e.g., the Fourier spectrum of windowed Gaussian noise) that accounts for the realistic random character of the simulated ground motion. The extension of the stochastic model to the finite-fault case requires transformations of the theoretical expressions that have been proposed for point sources to account for the finite dimensions of the sources that produce large earthquakes. The fault plane is discretized into a certain number of equal rectangular elements (subfaults) with dimensions $\Delta l \times \Delta w$. Each subfault is then treated as a point source with an $\omega^{-2}$ spectrum, and can be fully defined by two parameters: the seismic moment, $m_{0}$, and the corner frequency, $f_{\mathrm{c}}$, of the subfault spectrum. The connection between these two parameters and the finite dimensions of the subfaults is established through two coefficients, $\Delta \sigma$ and $\kappa$, respectively. In detail, assuming the simple case for which $\Delta l=\Delta w$, the subfault moment, $m_{0}$, can be determined from the following relation:

$$
m_{0}=\Delta \sigma \cdot \Delta l^{3}
$$

where $\Delta \sigma$ is a stress parameter, most closely related to the static stress drop (Beresnev and Atkinson, 1997). $\Delta \sigma$ relates the subfault moment to its finite 
dimensions. On the other hand, $\kappa$ relates the subfault spectrum corner frequency, $f_{\mathrm{c}}$, to its finite dimensions, through the relation:

$$
\kappa=\frac{f_{\mathrm{c}} \cdot \Delta l}{\beta}
$$

where $\beta$ is the shear-wave velocity. The parameter $\kappa$ actually controls the level of high-frequency radiation in the simulated time history and is equal to:

$$
\kappa=\frac{y z}{\pi}
$$

where $y$ is the ratio of rupture velocity to shear wave velocity and $z$ is linked to the maximum rate of slip, $v_{\mathrm{m}}$, on the fault plane through the equation:

$$
v_{\mathrm{m}}=\left(\frac{2 y z}{e}\right)\left(\frac{\Delta \sigma}{\rho \beta}\right)
$$

where $e$ is the base of the natural logarithm and $\rho$ is the density. The value of $z$ depends on a convention in the definition of the rise time as it is introduced in the exponential functions that describe the $\omega^{-2}$ model and for standard conventions $z=1.68$ (Beresnev and Atkinson, 1997, 1998). Due to the uncertainties involved in the definition of $z$, its value is allowed to vary through a parameter called sfact, practically a 'free' parameter during the implementation of the method.

\section{Results on rock sites}

\subsection{Source AND PROPAGation-PATH PROPERTIES}

With respect to the city of Thessaloniki, the earthquake of 20 June, 1978 (M6.5) can be considered as an intermediate-field event $(R \sim 30 \mathrm{~km})$. The event has been extensively studied (Soufleris and Stewart, 1981; Soufleris et al., 1982; Papazachos and Carydis, 1983; Stiros and Drakos, 2000; Tranos et al., 2003 and references therein). The mainshock was clearly produced by the rupture of a normal fault (see Table I for parameters) along WNWESE striking planes $\left(273-287^{\circ}\right)$ and dipping to the NNE with dip angles ranging from $43^{\circ}$ to $55^{\circ}$. The fault-length estimates vary between 16 and $35 \mathrm{~km}$, the fault width is $\sim 17 \mathrm{~km}$ from aftershock activity and seismic source studies. 


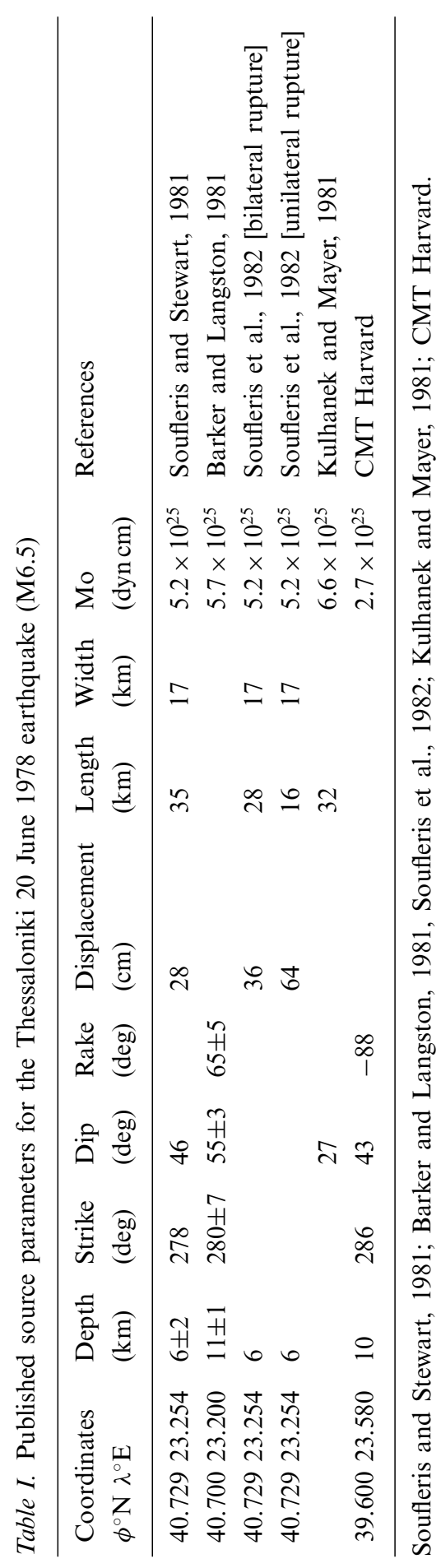


We calculate a subsurface rupture length of $23.5 \mathrm{~km}$ and down-dip rupture width of $13.5 \mathrm{~km}$ using the relations valid for normal faulting earthquakes (Wells and Coppersmith, 1994). These values are also comparable to the ones predicted by global scaling relations applicable to normal faulting in continental areas (Papazachos et al., 2004) and to the model of unilateral and bilateral rupture hypothesis lengths (Soufleris et al., 1982). The fault length of $\sim 24 \mathrm{~km}$ we assume is shorter than that obtained from 3 months of aftershock activity, which varies from 28 to $35 \mathrm{~km}$. However, this is to be expected as late aftershock activity spreads out in both fault edges enlarging its length, apart from the fact that aftershocks diffuse in nearby faults as well. The rupture width we adopt, $\sim 14 \mathrm{~km}$, is also $\sim 25 \%$ smaller than the $17 \mathrm{~km}$ of previous estimates (Soufleris and Stewart, 1981; Soufleris et al., 1982). In those studies, it is asserted that a down-dip length of $17 \mathrm{~km}$ is the maximum likely and may be an overestimate as it assumes that the rupture reached the surface, where faulting was small and discontinuous. Moreover, by assuming aftershocks hypocenter depths in the range from about 2 to $12 \mathrm{~km}$ and an average dip angle of about $45^{\circ}$, a fault width of $14 \mathrm{~km}$ results. For our calculations, the propagation path characteristics, namely the $Q \mathrm{p}$ and $Q$ s values in layers between the causative fault and the affected city, are of the form $Q=100 f^{0.8}$ (Hatzidimitriou, 1993, 1995).

Figure 2 gives a schematic representation of the causative normal fault of the 20 June, 1978 event as used in the strong-motion simulations. Based on the relation $\log \Delta l=-2+0.4 M$ (Beresnev and Atkinson 1999), the fault plane was divided in $5 \times 3$ sub-faults along length and width, respectively. Parameter sfact was taken equal to $1.5-\mathrm{a}$ value corresponding to an average obtained from a large number of forward simulations (Beresnev and Atkinson, 2001a,b), which has also been used successfully for normal fault rupture simulations in Greece (Roumelioti et al., 2004). To cover all possible rupture scenarios, six rupture-initiation points were considered, covering almost every reasonable possibility. Rupture initiation in the upper $4 \mathrm{~km}$ part of the fault was not taken as a possible scenario since hypocenter depth estimates vary from 6 to $11 \mathrm{~km}$ (see Table I). Furthermore, to incorporate the uncertainty due to the lack of information about the slip distribution during the modeled earthquake, we examined 30 random slip distributions. Therefore, the synthetic strong-motion parameter values presented in this study correspond to the means of the results of $30 \times 6$ (random slip distribution scenarios $\times$ tested rupture initiation points) simulations. The grid points where forward modeling values were estimated are included between $40.52^{\circ} \mathrm{N}$ to $40.77^{\circ} \mathrm{N}$ and $22.83^{\circ} \mathrm{E}$ to $23.09^{\circ} \mathrm{E}$. Grid spacing was taken $0.5 \mathrm{~km} \times 0.5 \mathrm{~km}$. 


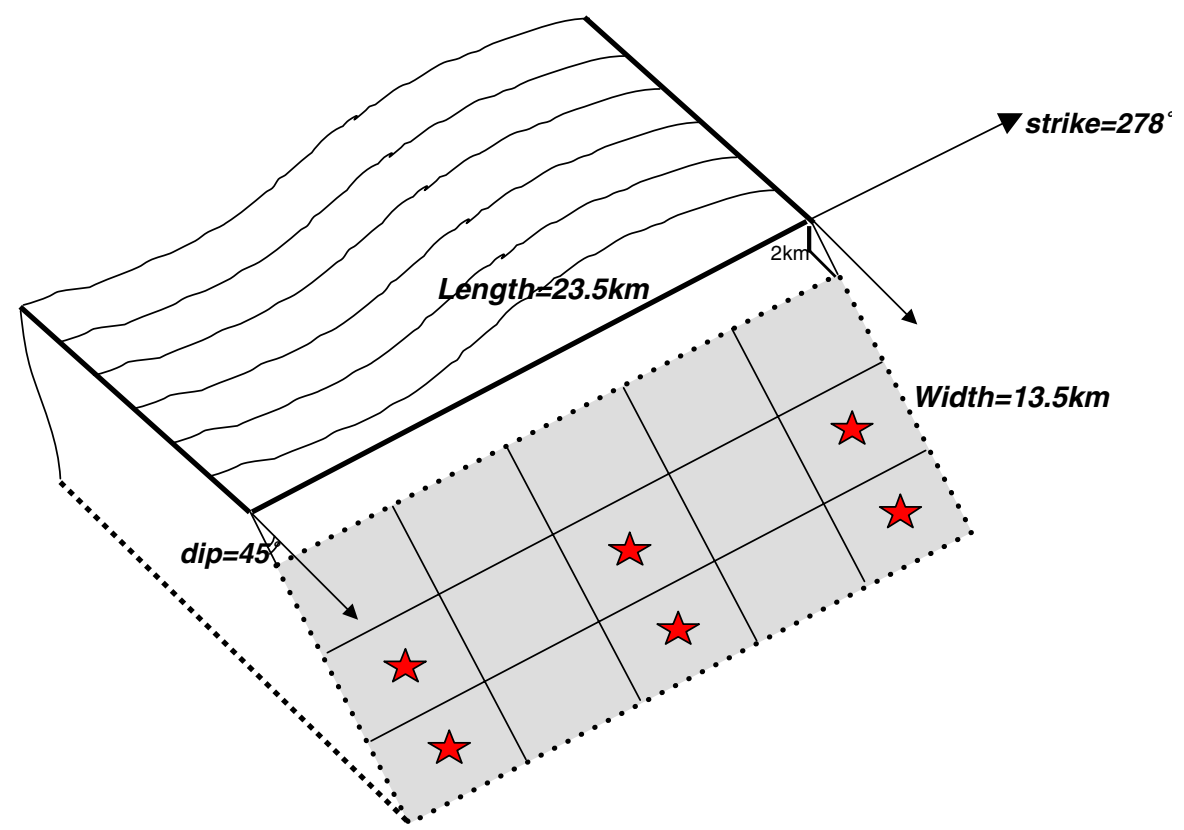

Figure 2. Schematic representation of the Thessaloniki 20 June 1978 earthquake fault geometry divided in $5 \times 3$ sub-faults used in strong motion simulation. Stars indicate rupture initiation scenarios.

\subsection{Peak Ground AND SPeCtral aCCELERATION SPECIFIED AT ROCK SITES}

In Figure 3, the simulation results on rock (site class B) are given as contour lines in terms of peak ground acceleration (PGA) and spectral acceleration (PSA) for natural periods equal to $0.2,0.6$, and $1.0 \mathrm{sec}$, respectively, using the stochastic method, source and propagation-path properties as given in Tables I and II. Simulated values of PGA on rock throughout the study area vary from 0.215 to $0.08 \mathrm{~g}$, of PSA $(T=0.2 \mathrm{sec})$ from 0.45 to $0.17 \mathrm{~g}$, of PSA $(T=0.6 \mathrm{sec})$ from 0.27 to $0.12 \mathrm{~g}$ and of PSA $(T=1.0 \mathrm{sec})$ from 0.13 to $0.06 \mathrm{~g}$. From the spatial distribution of strong ground motion it is evident that attenuation rate is decreasing from high frequencies (ratio of lower to higher strong motion value $=1: 2.7)$ to lower frequencies $(1: 2.2)$ as it was expected from empirical spectral acceleration attenuation relations applicable to Greece (Theodulidis and Papazachos, 1994). In order to examine uncertainties of the simulated values on rock, variation of standard deviation - as percentage of the mean PGA - with mean PGA is shown in Figure 4. For PGA values less than $0.2 \mathrm{~g}$ standard deviation fluctuates between $19 \%$ and $25 \%$ of the mean PGA. But for higher PGA values it increases for the examined area up to $33 \%$, reflecting the near field effects. It is clear that synthetic values carry inherently the uncertainty due 
Table II. Modeling parameters used to stochastically simulate strong ground motion from the Thessaloniki earthquake of June 20, 1978

\begin{tabular}{ll}
\hline Parameter & Value \\
\hline Fault orientation & Strike $278^{\circ}$, Dip $45^{\circ}$ \\
Fault dimensions & Length $23.5 \mathrm{~km}$, Width $13.5 \mathrm{~km}$ \\
Depth to upper edge of the fault & $2 \mathrm{~km}$ \\
Mainshock moment magnitude & 6.4 \\
Stress drop & $50 \mathrm{bars}$ \\
Number of subfaults along strike and dip & $5 \times 3$ \\
Crustal shear wave velocity & $3.3 \mathrm{~km} / \mathrm{sec}$ \\
Crustal density & $2.72 \mathrm{~g} / \mathrm{cm}^{3}$ \\
Parameter controlling high-frequency level & 1.5 \\
Parameter $\kappa$ & 0.035 \\
Parameters of the attenuation model & $100,0.8$ \\
$Q_{0}, \eta\left[Q(f)=Q_{0} * f^{\eta}\right]$ & \\
Geometric spreading & $(1 / R$ model) \\
Distance-dependent duration (sec) & Equal to: source duration $(\tau)$ for $R \leq 40 \mathrm{~km}$ \\
Slip distribution model & and to $\tau+0.05 R$ for $R \geq 40 \mathrm{~km}$ \\
\hline
\end{tabular}

to the insufficient knowledge of parameters such as the exact location of the rupture initiation point and the distribution of slip on the fault plane. That is the reason why standard deviation increases geometrically at higher PGA levels, that is, at sites closer to the causative fault.

\section{Results on soil sites}

\subsection{Site SOIL CHARACTERIZATION}

There are several approaches to site soil characterization based mainly on geological, geotechnical, and geophysical data coming from in situ or/and in laboratory experiments. The aim of our effort was to characterize Thessaloniki metropolitan area according to NEHRP soil categories. For the largest part of the metropolitan area of Thessaloniki a big amount of such data have been published during the last 30 years (among others; Tsotsos and Pitilakis, 1986; Tsotsos and Zissis-Tegos, 1986; Pitilakis et al., 1992; Anastasiadis et al., 2001; RISK-UE Report, 2003). To extend our knowledge mainly for the northern and southeastern part of the metropolitan area of Thessaloniki (Figure 5), where geotechnical/geophysical information was sparse or inadequate, we additionally utilized all available geological 

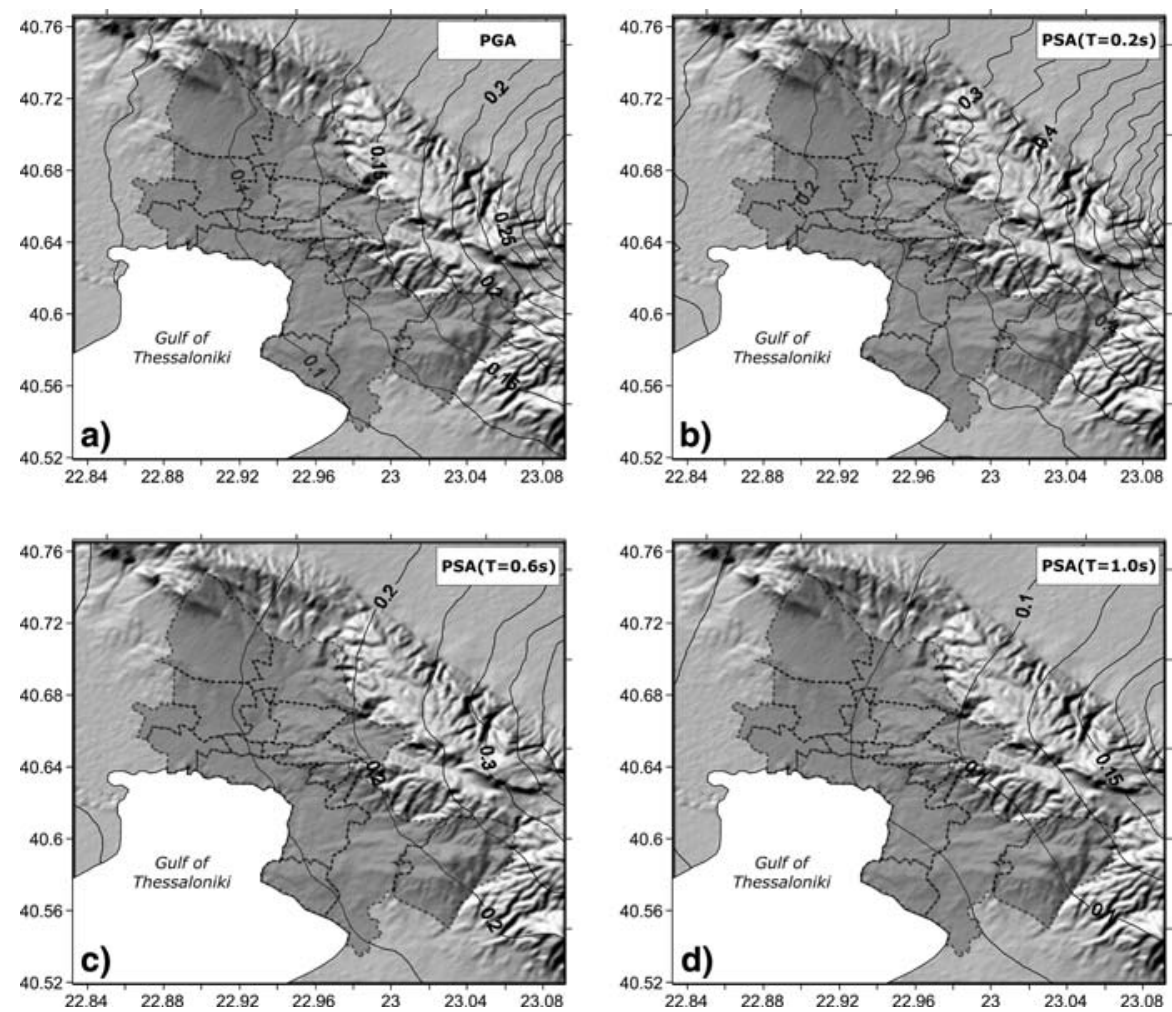

Figure 3. Contour lines of equal peak ground acceleration (PGA), spectral accelerations PSA $(0.2 \mathrm{sec})$, PSA $(0.6 \mathrm{sec})$ and PSA $(1.0 \mathrm{sec})$, in $g$, for soil category B according to NEHRP, estimated from stochastic strong ground simulation, produced by the fault of the Thessaloniki 20 June 1978 main shock.

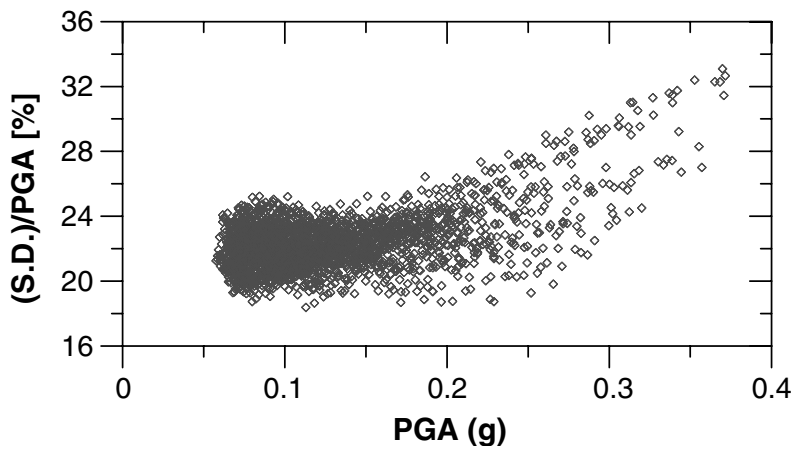

Figure 4. Variation of standard deviation ( $\%$ of peak ground acceleration) as a function of mean peak ground acceleration resulting from stochastic modeling. 


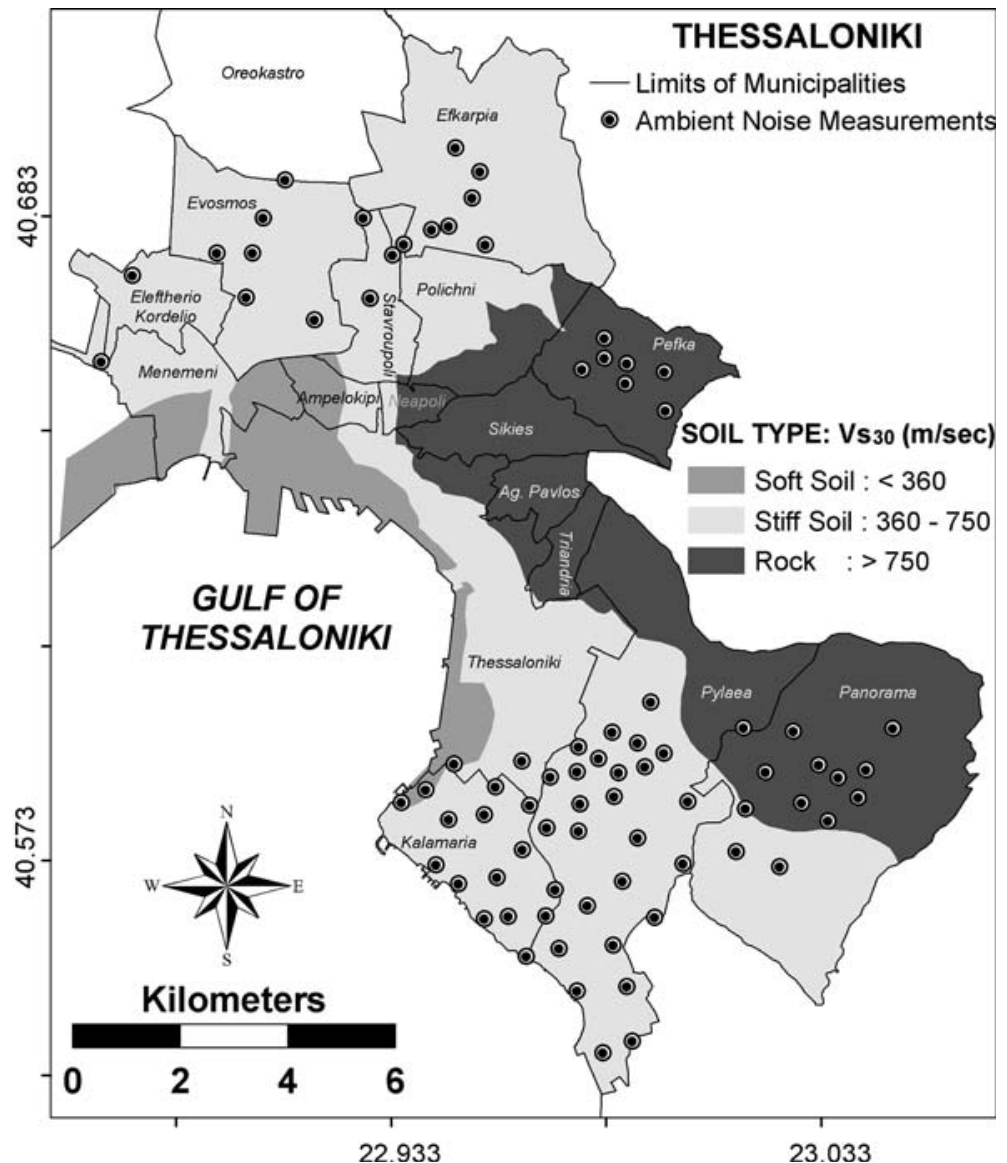

Figure 5. Compiled map of the metropolitan area of Thessaloniki showing three soil type categories (B: rock, C: stiff soil, D: soft soil) according to NEHRP. Circles with black dot center indicate sites where ambient noise measurements were performed.

and geotechnical information (IGME, 1978; Geotech. Engin. Div. Report, 1985; IGME, 1998). Based on the aforementioned information, a map of the metropolitan area of Thessaloniki was compiled including three soil categories according to NEHRP provisions, namely, soil category rock B $\left[V_{\mathrm{s} 30}>750 \mathrm{~m} / \mathrm{sec}\right]$, stiff soil C $\left[360 \mathrm{~m} / \mathrm{sec}<V_{\mathrm{s} 30}<750 \mathrm{~m} / \mathrm{sec}\right]$, and soft soil D $\left[180 \mathrm{~m} / \mathrm{sec}<V_{\mathrm{s} 30}<360 \mathrm{~m} / \mathrm{sec}\right]$ (Figure 5).

In order to better qualitatively evaluate and check NEHRP's site soil characterization as mentioned above, we performed ambient noise measurements of $20 \mathrm{~min}$ duration each in the northern and southeastern part of the metropolitan area of Thessaloniki (Figure 5). The $(\mathrm{H} / \mathrm{V})$ spectral ratio technique was used to obtain relevant 'transfer function' (e.g., Nakamura, 1989; Field and Jacob, 1993; Lachet and Bard, 1994; Lermo and Chavez-Garcia, 1994). 
Ambient noise data were processed in two stages. First, for each ambient noise recording, a number of windows, having a duration of $20 \mathrm{sec}$ each, were selected using the 'window selection' module of the JSESAME software (Atakan et al., 2004a,b; Theodulidis et al., 2004; SESAME project, 2005), in order to exclude portions with unrealistically large amplitudes or spikes, as has been also suggested by Duval et al. (2004). Using the ' $\mathrm{H} / \mathrm{V}$ processing' module of the JSESAME software, the ambient noise data were processed as follows: (a) offset correction, (b) computation of Fourier spectra in all three components (E-W, N-S, UP), (c) application of a cosine taper, (d) smoothing of the Fourier amplitude spectra by a Konno-Ohmachi algorithm (Konno and Ohmachi, 1998). For each frequency point the horizontal recording spectrum was divided by the vertical one, separately for the two horizontal components, in order to detect any significant difference between the EW/V and NS/V spectral ratios.

The (H/V) spectral ratios were grouped in two categories, namely, rock (soil class B) and stiff soil (soil class C), where the vast majority of ambient noise measurements were performed (Figures 6 and 7). Since for soil class D there are only three sites adjacent with soil class $C$, corresponding $(\mathrm{H} / \mathrm{V})$ ratios are not presented herein. In Figure 6, it can be clearly observed that there is no visible concentration of peaks with amplitude greater than 2 for frequencies less than about $2 \mathrm{~Hz}$. The majority of spectral ratios are flat thus indicating lack of site effects, which in turn means a 'rock' site. On the contrary, in Figure 7 the majority of spectral ratios with amplitudes ranging from about 2 to 8 show a fundamental peak concentration at frequencies less than $1.5 \mathrm{~Hz}$, thus indicating a site effect potential that may be attributed to stiff or even soft soil categories. These results supplementary support the soil classification according to NEHRP's B, C, D soil categories.

\subsection{PEAK GROUND AND SPECTRAL ACCELERATION SPECIFIED AT SOIL Sites}

By using the corresponding amplification factors (NEHRP, 1994), we computed strong ground motion for soil types $\mathrm{C}$ and $\mathrm{D}$ in terms of PGA, PSA $(0.2 \mathrm{sec})$, PSA $(0.6 \mathrm{sec})$, and PSA $(1.0 \mathrm{sec})$ (Figure $\left.8_{1}-8_{4}\right)$. In the same set of figures, we also plotted the respective ground-motion estimates obtained by employing the site amplification factors proposed by Anastasiadis and Klimis (2002) for soil types C and D for input motion given at soil category B. These amplification factors were determined on the basis of 1D modeling of well-documented soil profiles by using synthetic and recorded accelerograms relevant to the seismotectonic environment of Greece. In this work, we intend to apply NEHRP's seismic provisions with respect to amplification factors as well as regional dependent amplification factors proposed for Greece by Anastasiadis and Klimis (2002) [hereafter $\mathrm{A}-\mathrm{K}]$, and compare ground motion results based on these two categories 


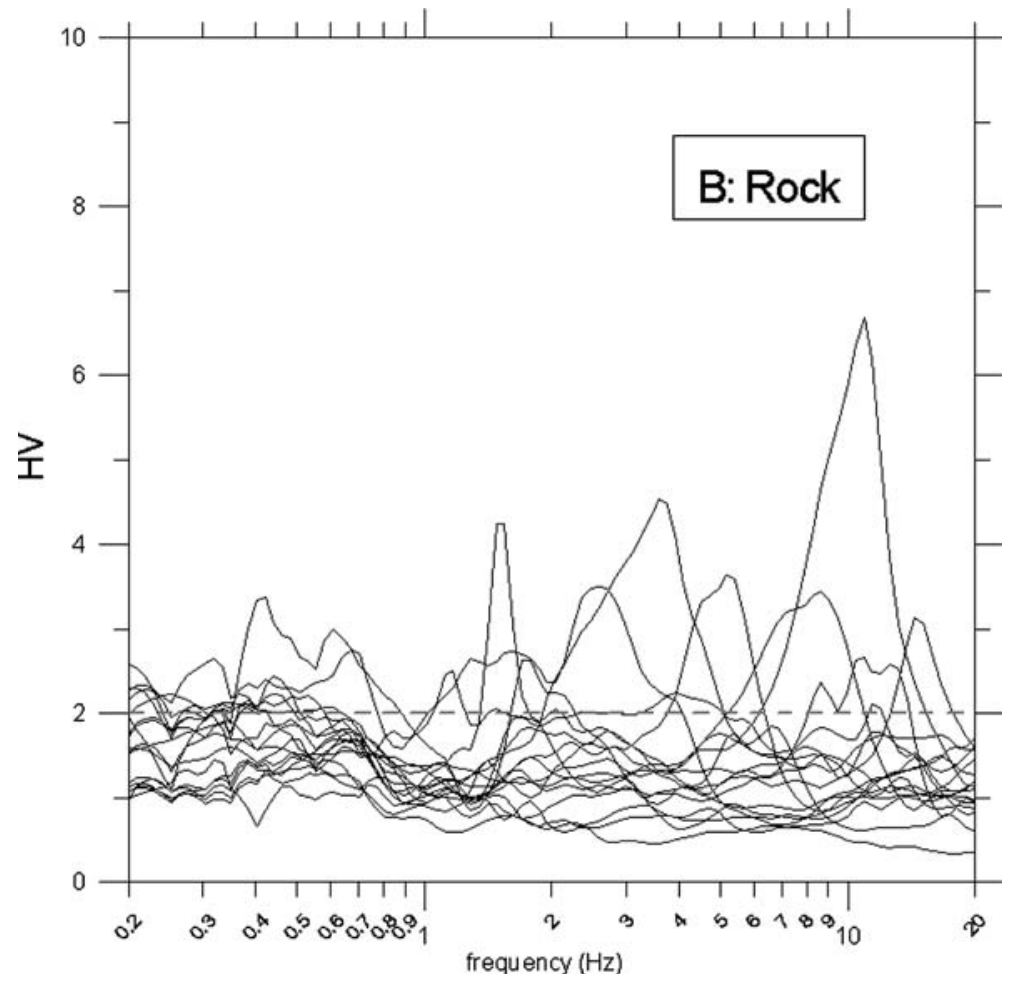

Figure 6. Horizontal-to-Vertical (H/V) spectral ratios obtained on rock site (B) of the map in Figure 5.

of amplification factors. The final aim is to correlate results from both approaches with observed macroseismic intensities in the metropolitan area of Thessaloniki and examine whether correlation is satisfactory. In maps of Figure $8_{1}-8_{4}$ distribution PGA and PSA $(T=0.2,0.6,1.0 \mathrm{sec})$ is presented. It is observed in Figures $8_{1}$ and $8_{2}$ that results based on NEHRP's amplification factors for soil category $\mathrm{D}$ are quite similar to those based on $\mathrm{A}-\mathrm{K}$ for soil category C. According to NEHRP, amplification factors at short periods $(\leq 0.3 \mathrm{sec})$ and relatively low level of shaking intensity $(<0.2 \mathrm{~g})$ for soil category D are comparable with amplification factors for soil category $\mathrm{C}$ proposed by $\mathrm{A}-\mathrm{K}$ (see Figure 10 of their paper). On the other hand, again according to NEHRP for shaking intensity around $0.2 \mathrm{~g}$, at short periods amplification factors for soil category $\mathrm{C}$ are similar with those of A-K for soil category $\mathrm{D}$. These observations clearly explain the origin of similarity between the PGA contours for soil $\mathrm{C}$ by using $\mathrm{A}-\mathrm{K}$ amplification factors with those for soil D of NEHRP (in Figure $8_{1}$ and $8_{2}$ ).

The validity of the estimated strong ground motion values was checked against the only recorded accelerogram of the June 20, 1978 main shock. The recording site (City Hotel) belongs to soil type D (Anastasiadis et al., 


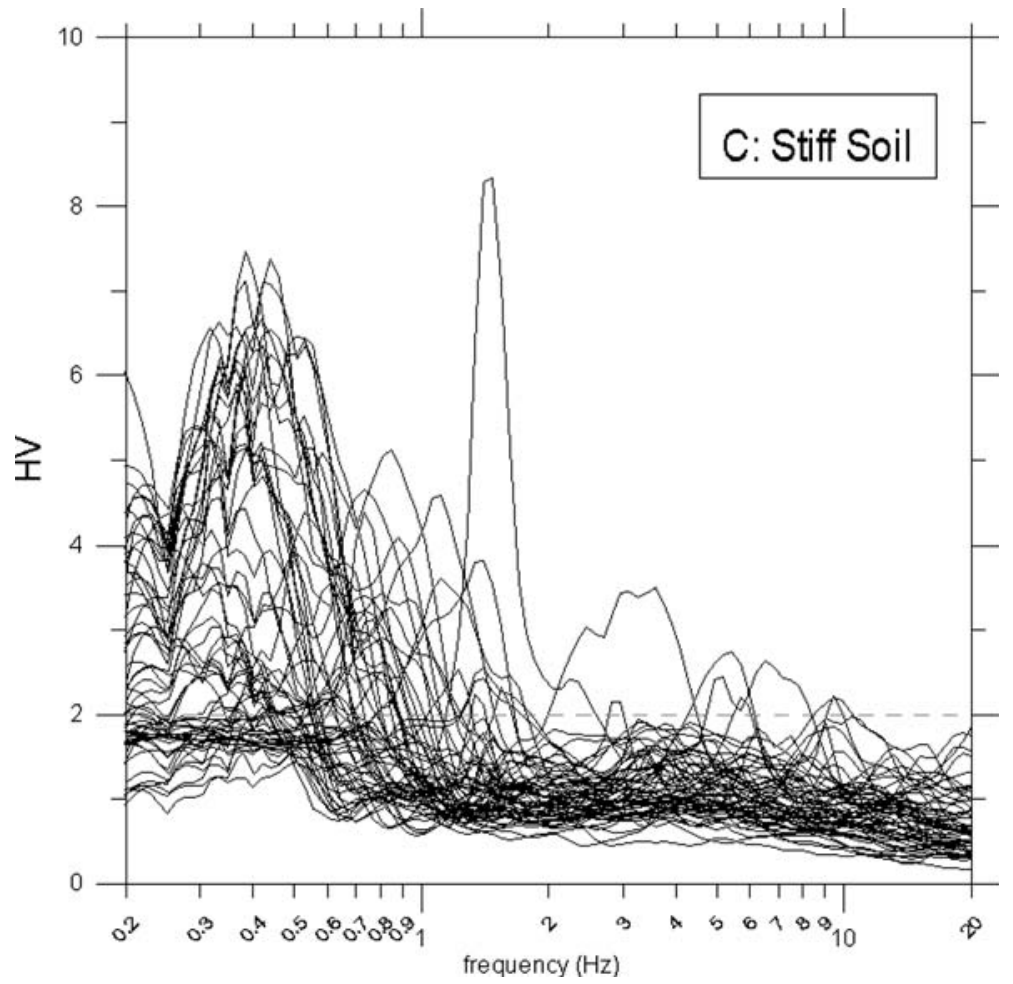

Figure 7. Horizontal-to-Vertical (H/V) spectral ratios obtained on stiff soil sites (C) of the map in Figure 5.

2001). Comparisons between the recorded (largest of the two horizontal components) and simulated values in terms of PGA and PSA (for $T=0.2$, 0.6 , and $1.0 \mathrm{sec}$ ) are shown in Figure 9. Both NEHRP and A-K amplification factors were used in the simulations. As can be seen (Figure 9), the simulated and observed values are in good agreement - with the exception of the A-K value at PSA $(1.0 \mathrm{sec})$, which is about half the observed one. In fact, for soil category $\mathrm{D}$ the amplification factors proposed by $\mathrm{A}-\mathrm{K}$ are generally in good agreement with those proposed by NEHRP with a striking exception for low-amplitude shaking intensity $(\sim 0.1 \mathrm{~g})$ and long periods $(\sim 1.0 \mathrm{sec})$ [see Figure 10 of $\mathrm{A}-\mathrm{K}$ paper]. This observation highlights the difference between the two approaches at PSA $(1.0 \mathrm{sec})$.

Although the comparison between synthetic PGA values and the unique strong motion recording of the 1978 earthquake is rather encouraging, an extensive test of the validity of our simulations is not possible due to lack of data. For this reason, we performed a test to show that the results of our method are compatible with the most recently proposed attenuation relations for Greece. We chose a single rupture initiation point (at the center of the assumed fault model for the 1978 earthquake) and 

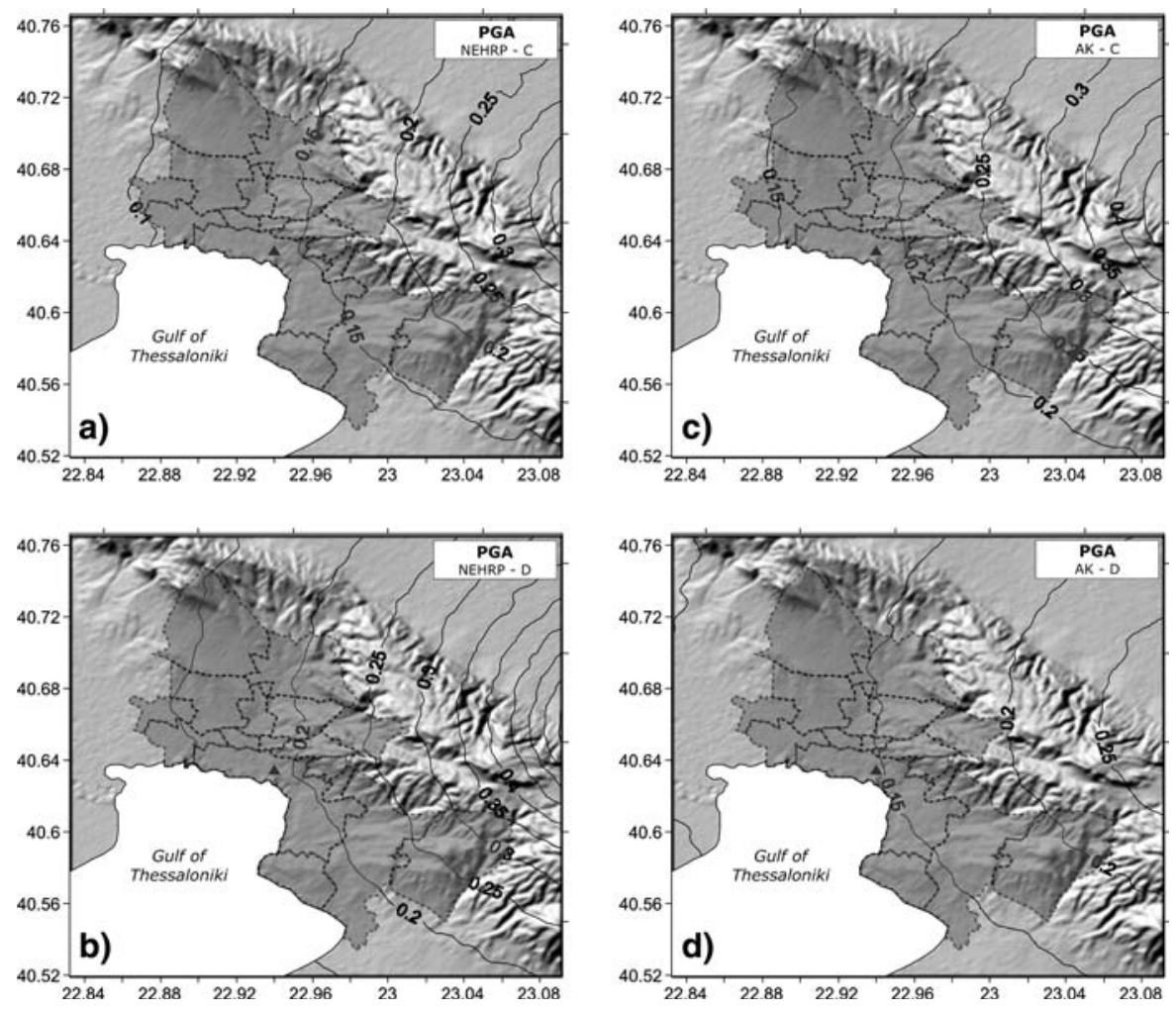

Figure $8_{1}$. Stochastic strong ground motion simulations produced from the rupture of the fault of the Thessaloniki 20 June, 1978 main shock. The black triangle marks the site of City Hotel where the unique accelerogram was recorded. Left panels show the results using amplification factors for soil type C and D according to NEHRP and right panels using amplification factors for soil type $\mathrm{C}$ and $\mathrm{D}$ according to Anastasiadis and Klimis (2002). ( $\left(8_{1}\right)$ Contour lines of equal peak ground acceleration (PGA) in $g$, for soil categories $\mathrm{C}$ and $\mathrm{D} ;\left(8_{2}\right)$ Contour lines of equal spectral acceleration (PSA) for natural period $0.2 \mathrm{sec}$, in $g$, for soil categories $\mathrm{C}$ and $\mathrm{D} ;\left(8_{3}\right)$ Contour lines of equal spectral acceleration (PSA) for natural period $0.6 \mathrm{sec}$, in $g$, for soil categories $\mathrm{C}$ and $\mathrm{D}$; $\left(8_{4}\right)$ Contour lines of equal spectral acceleration (PSA) for natural period $1.0 \mathrm{sec}$, in $g$, for soil categories C and D. See following pages for Figures $8_{2}-8_{4}$.

computed synthetics at points at different distances $(5-40 \mathrm{~km}$ with a step of $5 \mathrm{~km}$ ) and azimuths (starting from fault normal and using a step of $30^{\circ}$ ). For each point we computed 30 synthetics corresponding to 30 random slip distributions and the used PGA values along each circle to compute a mean PGA on rock, for each epicentral distance (by this we smooth out directivity and radiation pattern effects). These mean \pm one standard deviation PGA values are then compared (Figure 10) with corresponding values from the empirical attenuation relation of Skarlatoudis et al. (2003). From the comparison made it is evident that there is a satisfactory 

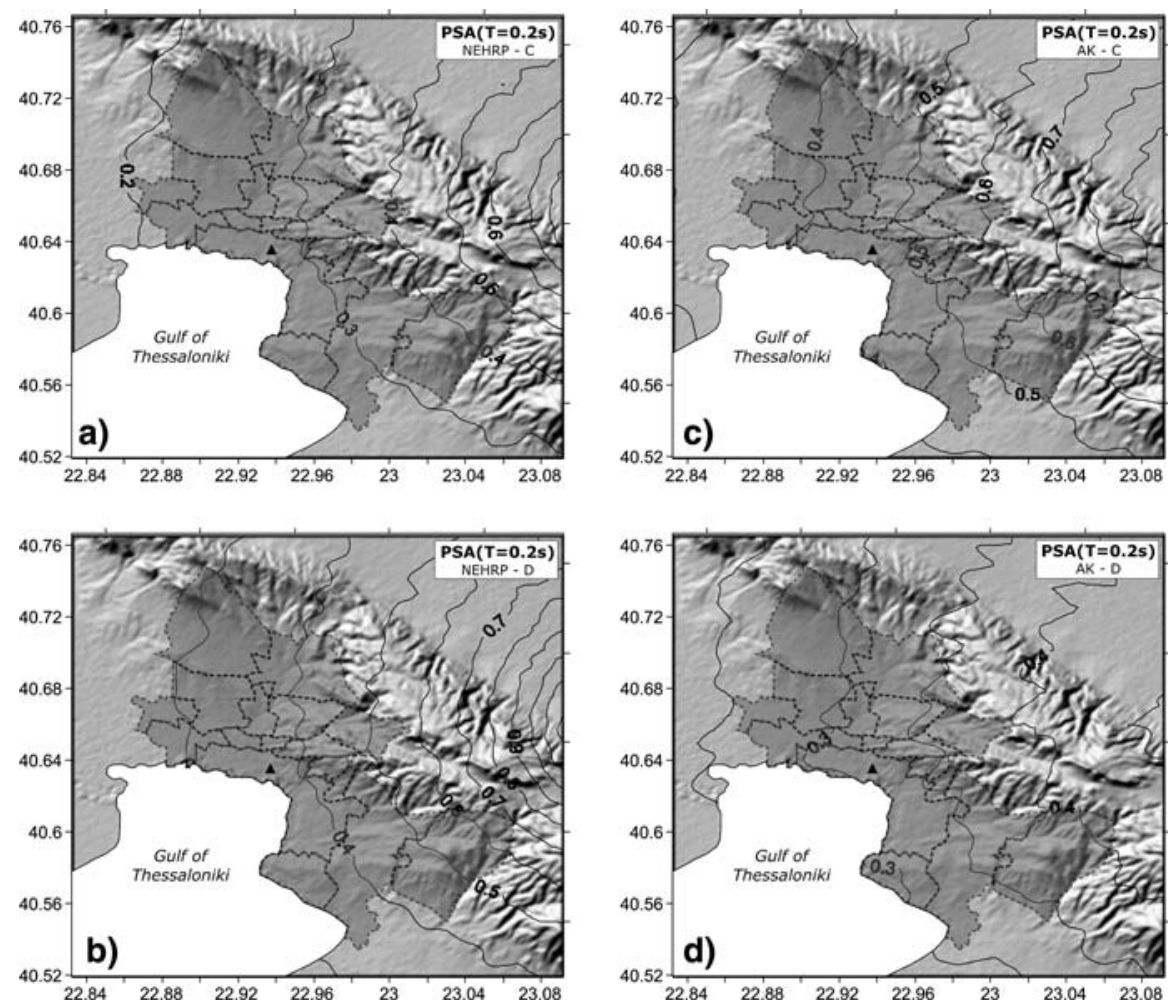

Figure $8_{2}$.

agreement between synthetic and empirical PGA for values less than $0.2 \mathrm{~g}$ where, as mentioned before, near-field effects are neglected or smoothed. On the other hand, the proposed attenuation relation for the area of Greece was based on a data set that had lack of near field $(R<20 \mathrm{~km})$ recordings for magnitude M6.5. Nonetheless, empirically predicted PGA values even in the near field fall within \pm one standard deviation of the synthetics.

\section{Correlation of macroseismic intensity with simulated ground motion}

Intensity is a semi-quantitative measure of strong shaking over an area based mainly on the buildings' behavior under seismic excitation due to a certain earthquake. Following the 20 June 1978 main shock, by employing the questionnaire method as traditionally applied in Greece, Leventakis (2003) compiled detailed MSK seismic-intensity maps, with an accuracy of \pm 0.1 . Two maps of equal intensity distribution were proposed, one incorporating all observed average macroseismic intensities ( $I_{\text {MSKobs }}$ ) and another for normalized ones to six-storey building ones ( $I_{\text {MSKnor }}$ ). 

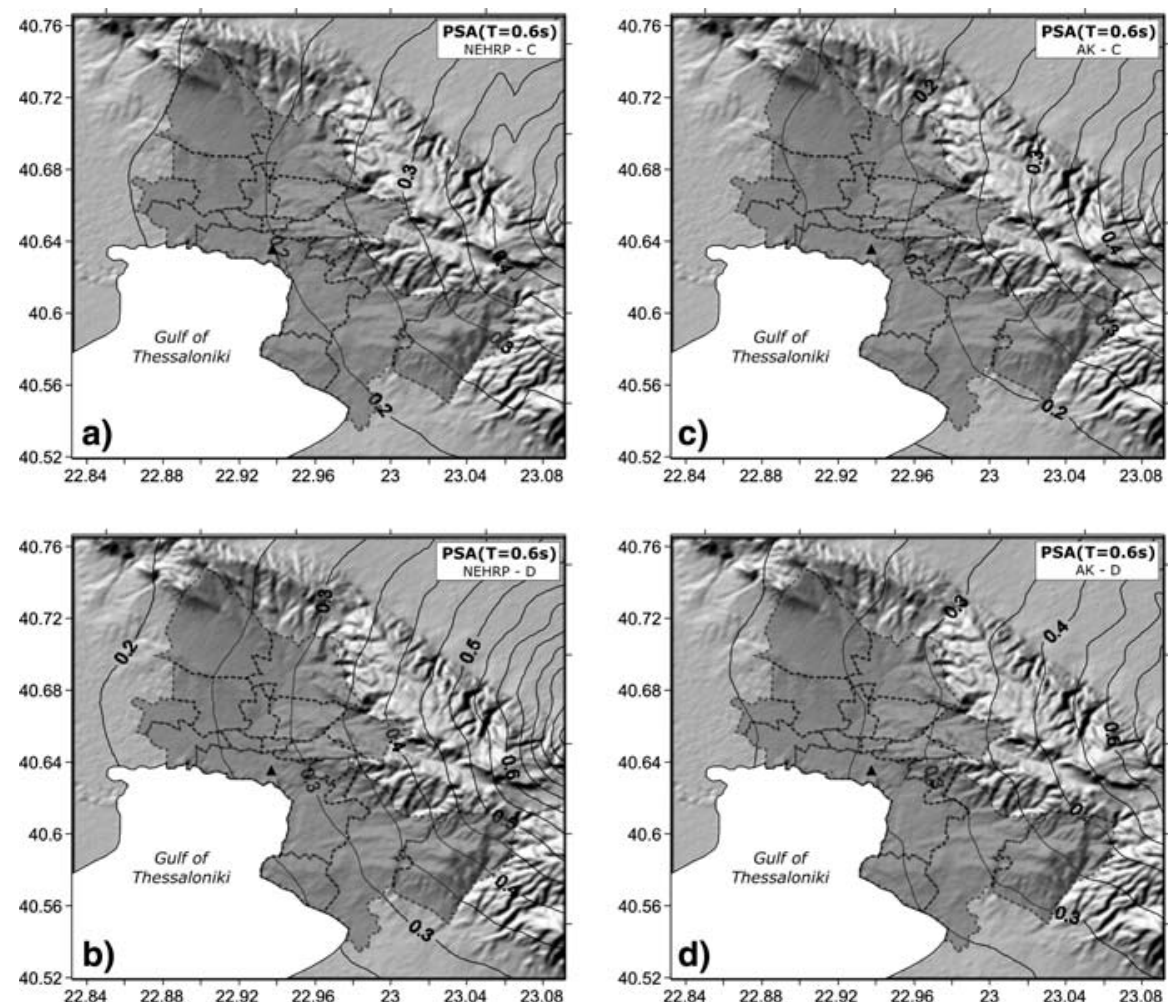

Figure 83 .

Although the overall features of both maps are similar, there are certain differences resulting from the normalization procedure applied. In the present study, intensities of both maps were compared quantitatively with strong motion values, but qualitative comparisons are shown only

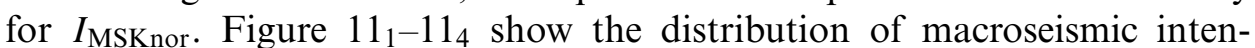
sity in MSK scale (Leventakis, 2003) where we superimposed the corresponding distributions of PGA and PSA (for $T=0.2,0.6$, and $1.0 \mathrm{sec}$ ) values, amplified according to NEHRP's amplification factors. A good qualitative comparison is visually obtained with higher PGA and PSA values correlating with the higher intensities and vise versa. In the part of the city close to the coast where macroseismic intensities are greater than VII, corresponding PGA values are higher than $0.17 \mathrm{~g}$, whereas at the northeastern part where macroseismic intensities are less than VI corresponding PGA values are mainly less than $0.14 \mathrm{~g}$. Similar qualitative correllation may be seen also for PSA $(T=0.2,0.6$, and $1.0 \mathrm{sec})$ values.

To make a quantitative comparison between macroseismic intensity and the simulated PGA and PSA $(T=0.2,0.6$, and $1.0 \mathrm{sec})$, for both NEHRP and A-K amplification factors, we fitted to the data with relations of the form, 

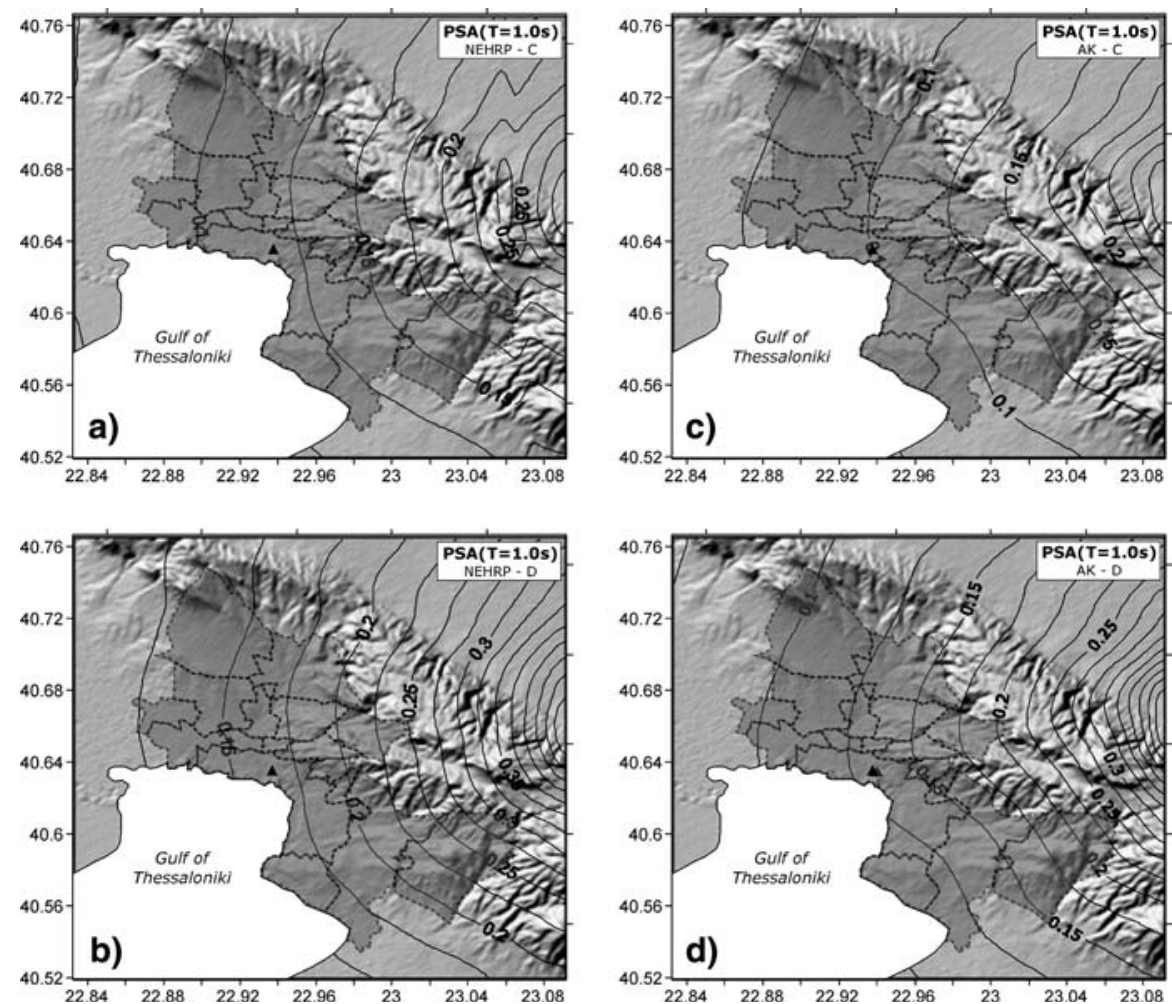

Figure 84 .

$$
\ln (Y)=a I+b
$$

where $Y$ is a dependent variable representing PGA and PSA values and $I$ is the macroseismic intensity.

The comparisons are shown in Figure 12 and the parameters are listed in Table III both for $I_{\text {MSKobs }}$ and $I_{\text {MSKnor }}$. For values resulting from A-K amplification factors [subscript $\mathrm{AK}$ ] a good correlation is visually observed only for spectral acceleration PSA $(0.6 \mathrm{sec})$ and PSA $(1.0 \mathrm{sec})$. To the contrary for values resulting from NEHRP's amplification factors a good correlation is visually observed for PGA and all spectral values examined.

To quantitatively check the linear dependence (correlation) of one variable (e.g., PGA) on another (e.g., $I$ ), we test the null hypothesis, $H_{0}$, of zero correlation, i.e. $r=0$, where $r$ is the correlation coefficient. We do this by the well-known two-tailed Student's $t$-test (e.g., Zar, 1984):

$$
t=r / s, \quad s=\left[\left(1-r^{2}\right) /(n-2)\right]^{1 / 2}
$$




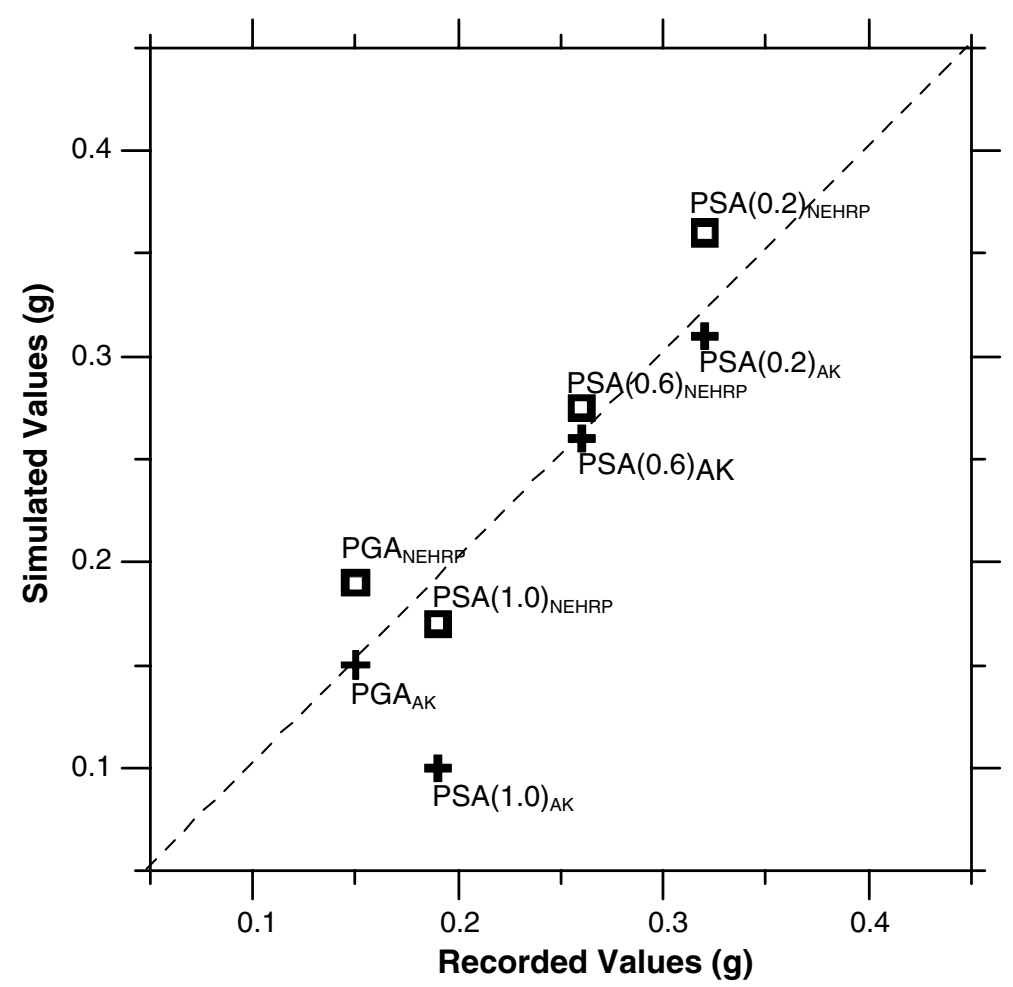

Figure 9. Comparison between recorded and predicted PGA and PSA (for $T=0.2$, 0.6, and $1.0 \mathrm{sec}$ ) values of the 20 June, 1978 main shock in the City Hotel (city centre; soil type D). Simulated values are given using the amplification factors both according to NEHRP (1994) [open squares] and Anastasiadis and Klimis (2002) [crosses].

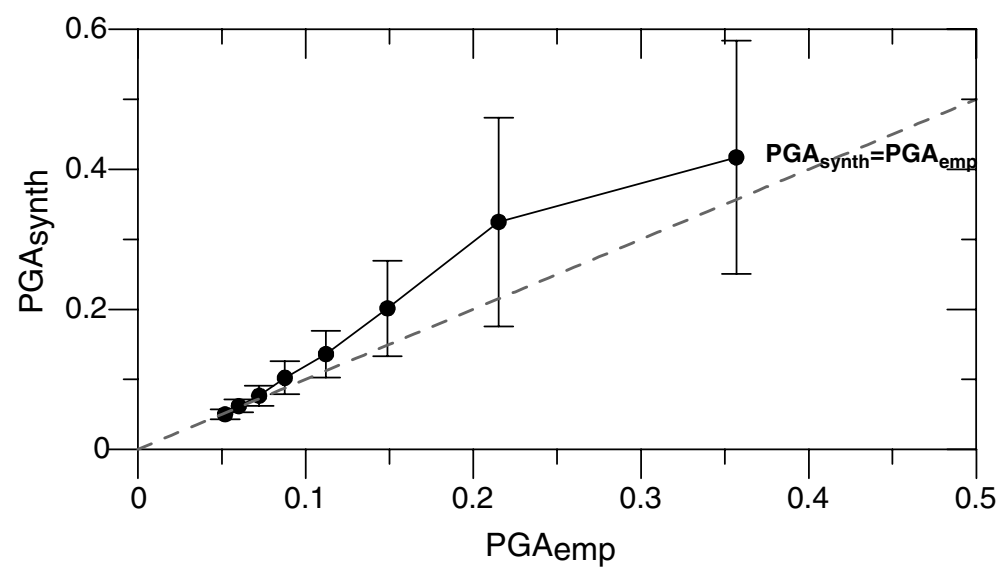

Figure 10. Comparison of peak ground acceleration based on empirical relation values $\left(\mathrm{PGA}_{\mathrm{emp}}\right)$ with the average \pm one standard deviation based on synthetic ones $\left(\mathrm{PGA}_{\text {synth }}\right)$. 


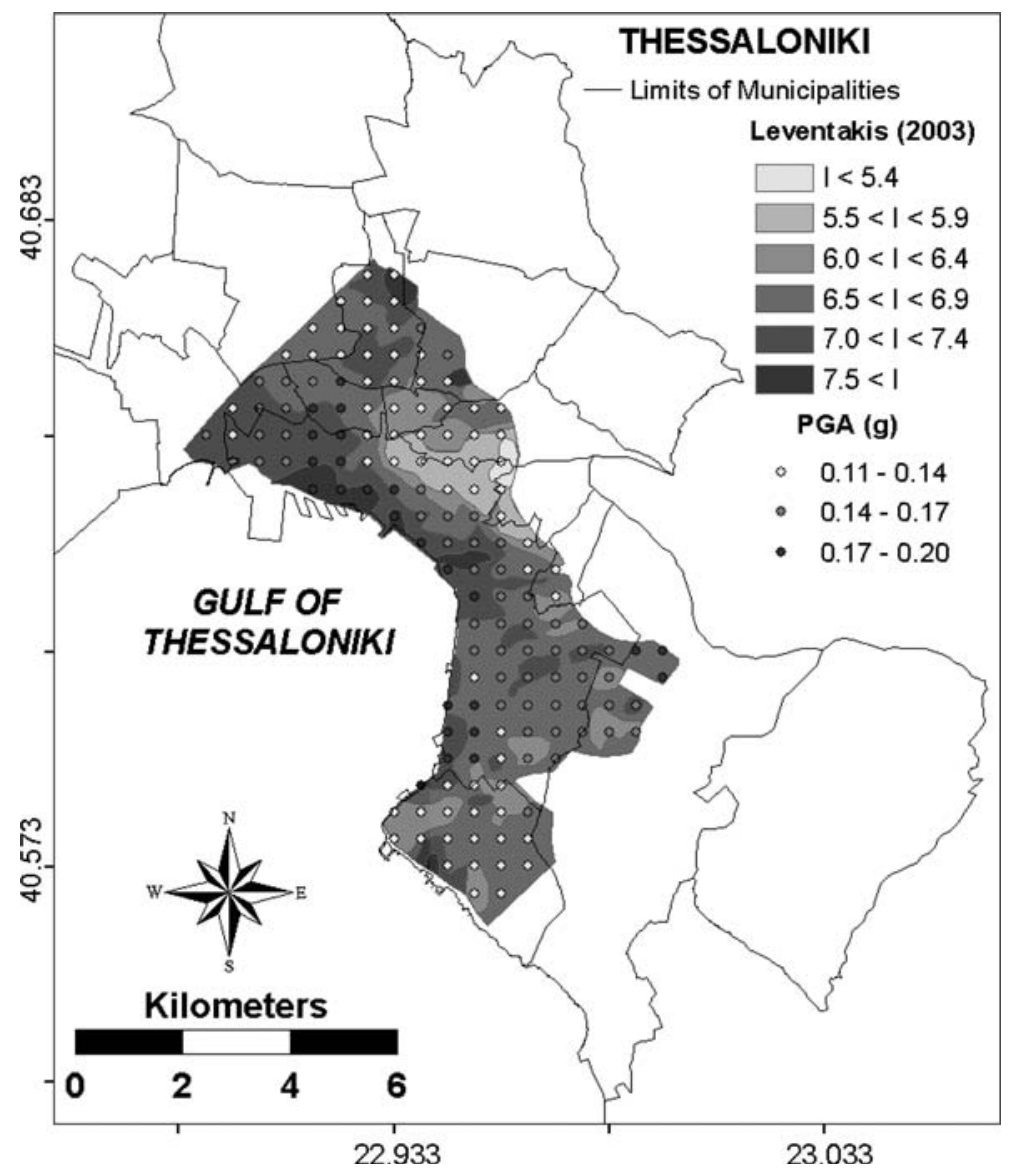

Figure $11_{1}$. Distribution of normalized macroseismic intensities for part of the metropolitan area of Thessaloniki (Leventakis, 2003); (11 $)$ underlain synthetic PGA values; $\left(11_{2}\right)$ underlain synthetic PSA values for $T=0.2 \mathrm{sec} ;\left(11_{3}\right)$ underlain synthetic PSA values for $T=0.6 \mathrm{sec}$ and $\left(11_{4}\right)$ underlain synthetic PSA values for $T=1.0 \mathrm{sec}$. See following pages for Figures $11_{2}-11_{4}$.

where $s$ is the standard error of the correlation coefficient and $n$ is the number of sample pairs. The null hypothesis is rejected (i.e. the two variables are considered to be linearly correlated) if

$$
-t_{\alpha(2) v} \geq t \geq t_{\alpha(2) v}
$$

where $t_{\alpha(2) v}$ is the $t$-value corresponding to level of significance $\alpha(2)$ ( 2 stands for two-tailed) and number of degrees of freedom $v=n-2 ; t_{\alpha(2) v}$ values are tabulated and can be found in relevant statistical tables.

Indeed the qualitatively seen correlation is supported by the $t$-test results presented in Table IV, with expected for $5 \%$ significance level, $t_{0.05}=1.98$. 


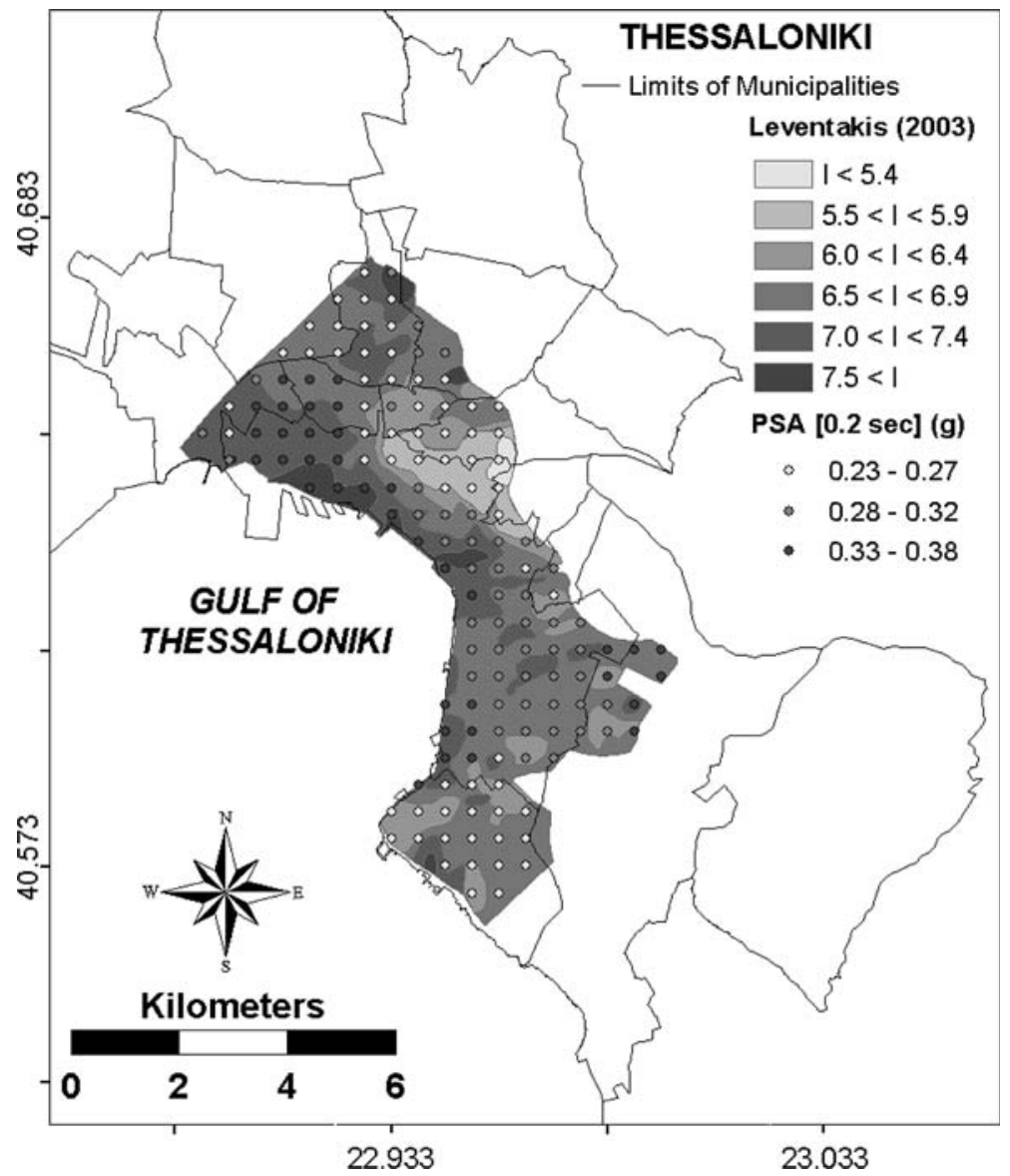

Figure $11_{2}$.

For values resulting from NEHRP's amplification factors, a satisfactory correlation is observed for all examined ground motions giving high $t$-test values (Table IV). To the contrary, results from AK's amplification factors show a satisfactory correlation only for spectral acceleration values PSA $(T=0.6$ and $1.0 \mathrm{sec})$. Figure 12 also indicates that the correlation between PGA, PSA and macroseismic intensity is slightly more robust when the NEHRP amplifications factors are used, compared to those of A-K. Especially for short natural periods $\left(T_{\mathrm{O}} \sim 0 \mathrm{sec}, T_{\mathrm{O}}=0.2 \mathrm{sec}\right)$ the latter do not exhibit any acceptable correlation as it can be also seen from the statistical parameters in Table IV. This difference is partly supported by the A-K result, namely, that amplification factors for soil category $\mathrm{C}$ appear to have maximum values from 1.8 to 2.0 for periods 0.2 to $0.4 \mathrm{sec}$, presenting a noticeable discrepancy from corresponding amplification factors of NEHRP. According to A-K these differences could be mainly attributed to the 


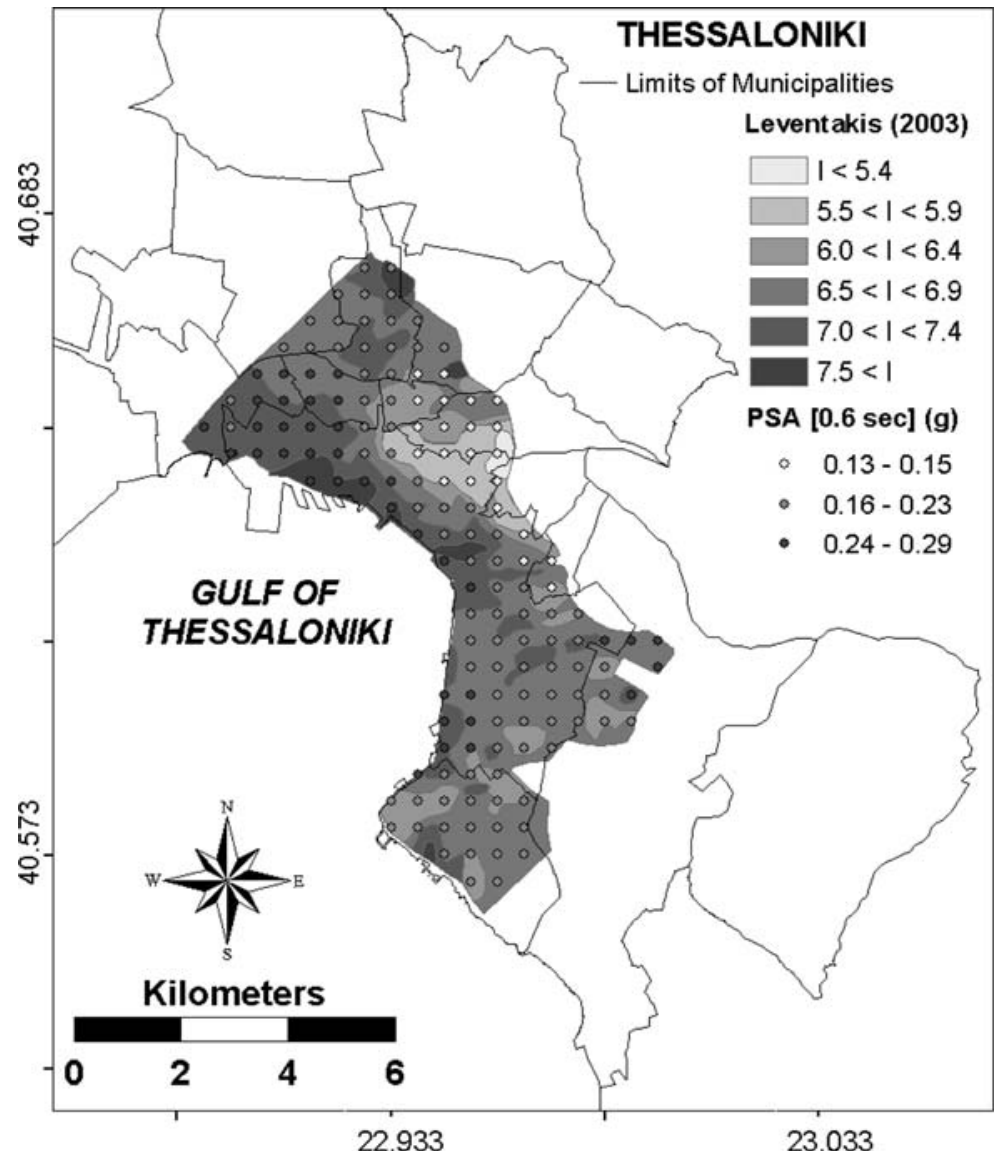

Figure $11_{3}$.

coincidence of predominant period of input motion $(0.1-0.4 \mathrm{sec})$ with the soil profile predominant period $(0.18-0.6 \mathrm{sec})$. This may result in 'high' calculated values of site amplification factor for low periods. The coefficient of the Eq. (7) takes higher values at intermediate periods $(0.6 \mathrm{sec} \leq$ $T \leq 1.0 \mathrm{sec}$ ) - almost double - than those at short periods $(T \leq 0.2 \mathrm{sec})$. That is, the rate of intensity increment with increasing strong ground motion is higher for intermediate period range.

The estimated strong ground-motion parameter values corresponding to NEHRP (1994) amplification factors show satisfactory correlation with observed macroseismic intensity for the entire period range examined. Despite their generic character, the choice of strong ground motion amplification factors proposed by NEHRP is encouraging given that the examined area has been properly classified with respect to soil categories. 


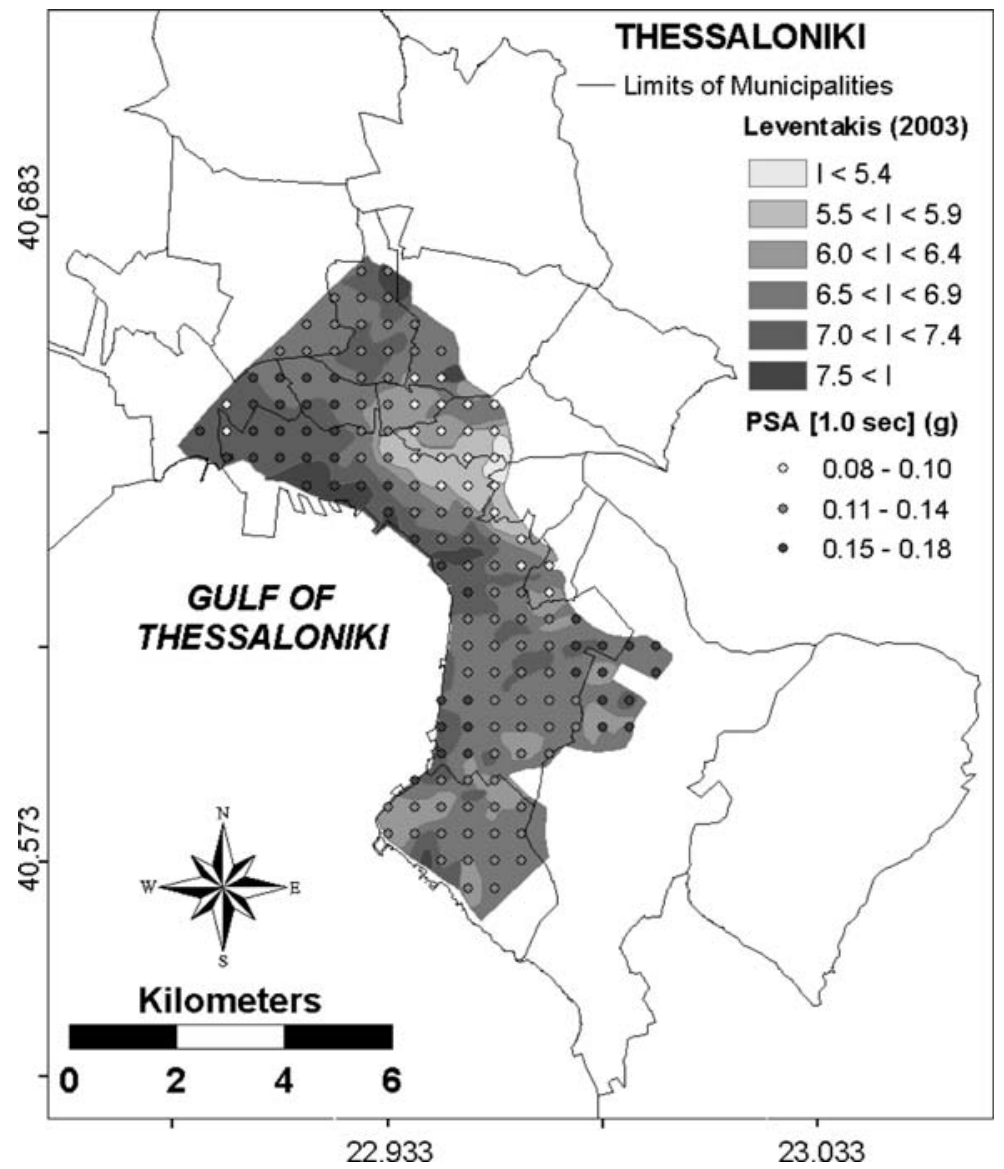

Figure $11_{3}$.

\section{Discussion and Conclusions}

We applied stochastic forward modeling using a finite-source model of the 20 June 1978 (M6.5) Thessaloniki (Northern Greece) main shock to simulate ground motion in terms of PGA and PSA (for $T=0.2,0.6$, and $1.0 \mathrm{sec}$ ). The ground motion parameters were estimated for rock (soil category B, NEHRP provisions) underlain stiff and soft formations in the metropolitan area of Thessaloniki. For soil category B, PGA values were found to vary between 0.08 and $0.21 \mathrm{~g}$ and PSA values between $0.06 \mathrm{~g}$ (longer periods) and $0.45 \mathrm{~g}$ (shorter periods).

Using amplification factors proposed by NEHPR (1994) and by Anastasiadis and Klimis (2002), strong ground motion on surface was estimated for soil categories $\mathrm{C}$ and $\mathrm{D}$ on a grid of $0.5 \mathrm{~km} \times 0.5 \mathrm{~km}$ throughout the metropolitan area of Thessaloniki. Validation of the simulation results was based on: (a) comparison of synthetic PGA values with those 

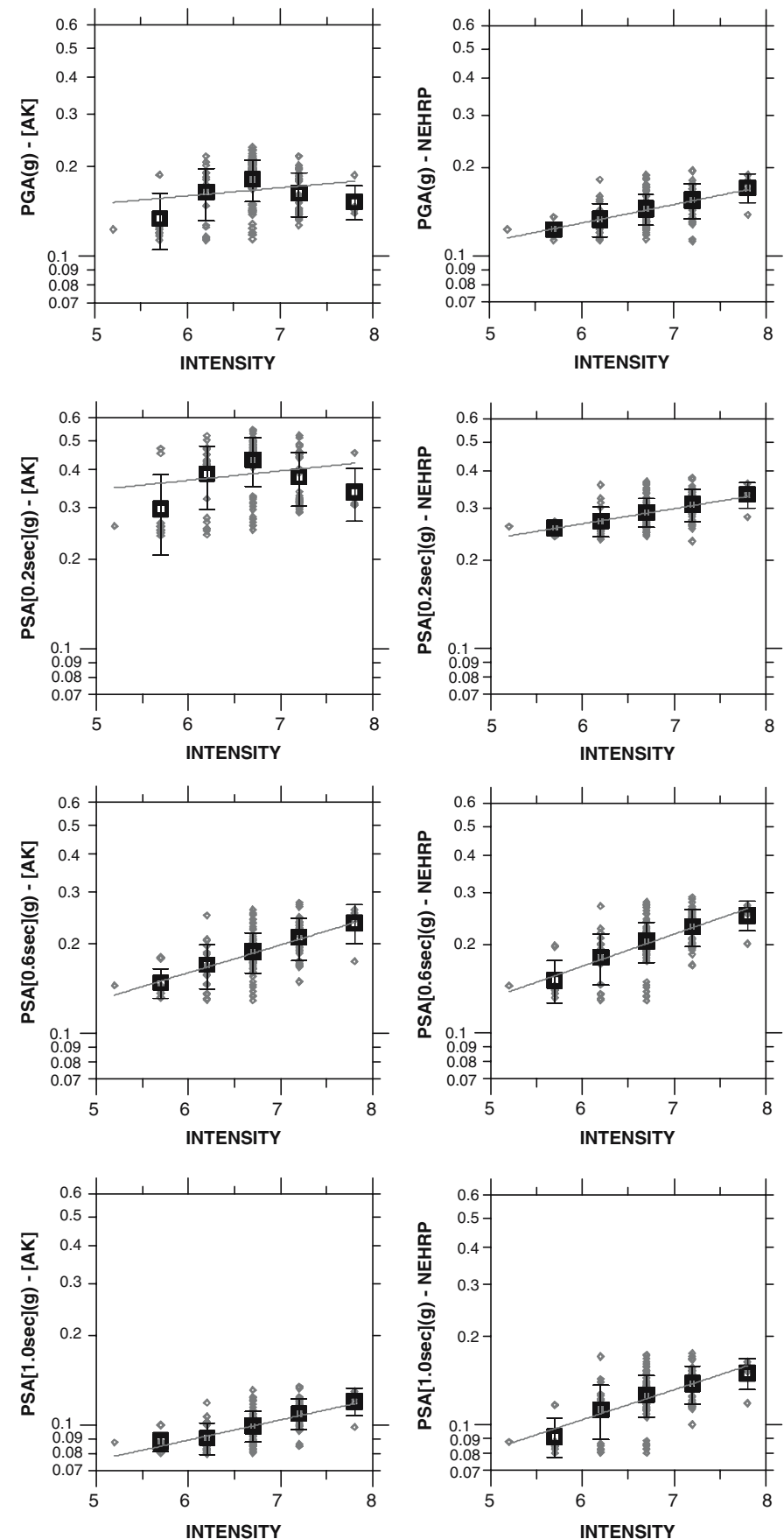

Figure 12. Correlation between macroseismic intensity, $I_{\mathrm{MSK}}$ (as shown in Figure $81-84$ ) and PGA, PSA (for $T=0.2,0.6$ and $1.0 \mathrm{sec}$ ). Left panels for amplification factors according to Anastasiadis and Klimis (2002) [AK], and right panels according to NEHRP (1994). 
Table III. Correlation between ground motion parameters (PGA and PSA) and the macroseismic intensity, $I_{\mathrm{MSK}}$ assuming linear fit of the form $\ln (Y)=a I_{\mathrm{MSK}}+b$

\begin{tabular}{|c|c|c|}
\hline $\begin{array}{l}\text { Ground motion } \\
\operatorname{parameter}(g)\end{array}$ & $\begin{array}{l}\text { Amplification factors by } \\
\text { Anastasiadis and Klimis (2002) }\end{array}$ & $\begin{array}{l}\text { Amplification factors } \\
\text { by NEHRP (1994) }\end{array}$ \\
\hline PGA & $\begin{array}{l}\ln (\text { PGA })=0.06 I_{\text {MSKobs }}-2.21 \\
\ln (\text { PGA })=0.06 I_{\text {MSKnor }}-2.21\end{array}$ & $\begin{array}{l}\ln (\mathrm{PGA})=0.14 I_{\text {MSKobs }}-2.89 \\
\ln (\mathrm{PGA})=0.14 I_{\text {MSKnor }}-2.91\end{array}$ \\
\hline PSA & $\begin{array}{l}\ln (\operatorname{PSA}[T=0.2 \mathrm{sec}])=0.07 I_{\text {MSKobs }}-1.43 \\
\ln (\operatorname{PSA}[T=0.2 \mathrm{sec}])=0.07 I_{\text {MSKnor }}-1.43\end{array}$ & $\begin{array}{l}\ln (\operatorname{PSA}[T=0.2 \mathrm{sec}])=0.11 I_{\text {MSKobs }}-2.00 \\
\ln (\operatorname{PSA}[T=0.2 \mathrm{sec}])=0.12 I_{\text {MSKnor }}-2.04\end{array}$ \\
\hline PSA & $\begin{array}{l}\ln (\operatorname{PSA}[T=0.6 \mathrm{sec}])=0.21 I_{\text {MSKobs }}-3.09 \\
\ln (\operatorname{PSA}[T=0.6 \mathrm{sec}])=0.22 I_{\text {MSKnor }}-3.13\end{array}$ & $\begin{array}{l}\ln (\operatorname{PSA}[T=0.6 \mathrm{sec}])=0.24 I_{\text {MSKobs }}-3.24 \\
\ln (\operatorname{PSA}[T=0.6 \mathrm{sec}])=0.25 I_{\text {MSKnor }}-3.28\end{array}$ \\
\hline PSA & $\begin{array}{l}\ln (\operatorname{PSA}[T=1.0 \mathrm{sec}])=0.15 I_{\text {MSKobs }}-3.29 \\
\ln (\operatorname{PSA}[T=1.0 \mathrm{sec}])=0.16 I_{\text {MSKnor }}-3.36\end{array}$ & $\begin{array}{l}\ln (\operatorname{PSA}[T=1.0 \mathrm{sec}])=0.23 I_{\text {MSKobs }}-3.66 \\
\ln (\operatorname{PSA}[T=1.0 \mathrm{sec}])=0.23 I_{\text {MSKnor }}-3.67\end{array}$ \\
\hline
\end{tabular}

The comparison is given separately for amplification factors by NEHRP (1994) and by Anastasiadis and Klimis (2002).

Table IV. Results of linear correlation analysis between PGA and $\operatorname{PSA}(T=0.2 \mathrm{sec}), \operatorname{PSA}(T=0.6 \mathrm{sec})$, $\operatorname{PSA}(T=1.0 \mathrm{sec})$ versus macroseismic intensity, $I_{\mathrm{MSK}}$

\begin{tabular}{|c|c|c|c|c|c|c|c|c|}
\hline Variables & $\mathrm{DF}_{\mathrm{obs}}$ & $\mathrm{DF}_{\text {nor }}$ & $r_{\mathrm{obs}}$ & $r_{\text {nor }}$ & $r(5 \%)$ & $t_{\mathrm{obs}}$ & $t_{\text {nor }}$ & $t(5 \%)$ \\
\hline $\mathrm{PGA}_{\mathrm{AK}}, I_{\mathrm{MSK}}$ & 147 & 147 & 0.16 & 0.15 & 0.16 & 1.90 & 1.84 & 1.98 \\
\hline PGA $_{\text {NEHRP }}, I_{\mathrm{MSK}}$ & 147 & 147 & 0.50 & 0.50 & 0.16 & 6.97 & 6.91 & 1.98 \\
\hline $\operatorname{PSA}(0.2 \mathrm{sec})_{\mathrm{AK}}, I_{\mathrm{MSK}}$ & 147 & 147 & 0.14 & 0.14 & 0.16 & 1.75 & 1.72 & 1.98 \\
\hline $\operatorname{PSA}(0.2 \mathrm{sec})_{\mathrm{NEHRP}}, I_{\mathrm{MSK}}$ & 147 & 147 & 0.45 & 0.45 & 0.16 & 6.03 & 6.13 & 1.98 \\
\hline $\operatorname{PSA}(0.6 \mathrm{sec})_{\mathrm{AK}}, I_{\mathrm{MSK}}$ & 147 & 147 & 0.55 & 0.55 & 0.16 & 8.05 & 7.97 & 1.98 \\
\hline $\operatorname{PSA}(0.6 \mathrm{sec})_{\mathrm{NEHRP}}, I_{\mathrm{MSK}}$ & 147 & 147 & 0.59 & 0.59 & 0.16 & 8.91 & 8.75 & 1.98 \\
\hline $\operatorname{PSA}(1.0 \mathrm{sec})_{\mathrm{AK}}, I_{\mathrm{MSK}}$ & 147 & 147 & 0.52 & 0.54 & 0.16 & 7.40 & 7.83 & 1.98 \\
\hline $\operatorname{PSA}(1.0 \mathrm{sec})_{\mathrm{NEHRP}}, I_{\mathrm{MSK}}$ & 147 & 147 & 0.57 & 0.55 & 0.16 & 8.31 & 7.96 & 1.98 \\
\hline
\end{tabular}

$\mathrm{DF}$ is the degrees of freedom $(=147) ; r$ is the correlation coefficient; $t$ is the student's $t$-test statistics; $r(5 \%)$ and $t(5 \%)$ are the corresponding values at the $5 \%$ significance level. The subscripts $A K$ and NEHRP denote incorporation of amplification factors by Anastasiadis and Klimis (2002) and by NEHRP (1994), respectively.

calculated from empirical relations proposed for Greece and surrounding area and (b) comparison with the unique accelerogram recorded during the main shock at the City Hotel (in the city center, soil category D). Both approaches showed satisfactory agreement between recorded or empirically calculated with synthetic values.

A detailed macroseismic survey for 12 municipalities of the study area, based on a questionnaire method (Leventakis 2003), provided sufficient number of intensity data (in MSK scale) for correlation with simulated strong ground motion both for NEHRP and A-K soil amplification 
factors. The resulting relations between the examined strong motion parameters (PGA, PSA) based on NEHRP's amplification factors and macroseismic intensity show satisfactory correlation for the entire spectral content examined. It must be pointed out that the proposed relations are based on rough soil categorization which does not take into account already detected 2D-3D site effects (Raptakis et al. 2004, Triantafyllidis et al. 2004) or possible non-linear phenomena in certain areas, especially in soil category D. However, the statistical robustness coming up from the data correlation clearly supports the idea that they may be used for prediction of expected damage distribution - in terms of macroseismic intensity-given strong ground motion caused by the occurrence of moderate-to-large events from seismic active faults in the vicinity of Thessaloniki metropolitan area.

We found that the rate of intensity increment with increasing strong ground motion is much higher for the intermediate-period range $(0.6 \mathrm{sec} \leq \mathrm{T}$ $\leq 1.0 \mathrm{sec})$ than for short periods $(T \leq 0.2 \mathrm{sec})$. Moreover, correlation coefficients (see Table IV) are also higher for the intermediate-period range. This observation is in good agreement with the fact that the majority of reinforced concrete buildings in Thessaloniki affected by the strong shaking of the 20 June 1978 mainshock, had 6-9 stories (Penelis et al., 1985), which-according to simple seismic code approximation $T_{o} \approx$ $0.1 \mathrm{n}(n=$ number of storey - corresponds to fundamental periods between 0.6 and about $1.0 \mathrm{sec}$. The coincidence of the buildings' natural periods with the ground-motion frequency content provides a possible explanation for the observed higher intensity increment in the corresponding period range being due to resonance phenomena.

\section{Acknowledgements}

This work was conducted in the framework of the project 'SeisImpactTHESS: a system to evaluate earthquake impact in urban areas' funded by the General Secretariat of Research and Technology (Ministry of Development of Greece). We are thankful to A. Anastasiadis for providing useful geotechnical data as well as fruitful discussions and to two anonymous reviewers for their contribution to significantly improving the paper.

\section{References}

Anastasiadis, A. and Klimis, N. (2002) Effect of soil non-linearities and site characteristics on evaluation of site coefficients, Paper No. 498, Proceedings of 12th European Conference on Earthquake Engineering.

Anastasiadis, A., Raptakis, D., and Pitilakis, K. (2001) Thessaloniki's detailed microzoning: subsurface structure site response analysis. Pageoph 158, 2597-2633. 
Anderson, J. and Hough, S. (1984) A model for the shape of the Fourier amplitude spectrum of acceleration at high frequencies, Bulletin of the Seismological Society of America 74, 1969-1993.

Atakan, K., Bard, P.-Y., Kind, F., Moreno, B., Roquette, P., Tento, A. and SESAME-Team (2004b) J-SESAME: a standardized software solution for the H/V spectral ration technique, Paper No. 2270, Proceedings of the 13th World Conference on Earthquake Engineering, Vancouver, August 2004.

Atakan, K., Duval, A.-M., Theodulidis, N., Guillier, B., Chatelain J.-L., Bard P.-Y. and SESAME-Team (2004a) The H/V spectral ratio technique: experimental conditions, data processing and empirical reliability assessment, Paper No. 2268, Proceedings of the 13th World Conference on Earthquake Engineering, Vancouver, August 2004.

Barker, J. and Langston, C. (1981) Inversion of teleseismic body waves for the moment tensor of the 1978 Thessaloniki, Greece, earthquake, Bulletin of the Seismological Society of America 71, 1423-1444.

Berardi, R., Jiménez, M.J., Zonno, G. and García-Fernández, M. (2000) Calibration of stochastic finite-fault ground motion simulations for the 1997 Umbria-Marche, Central Italy, earthquake sequence. Soil Dynamics and Earthquake Engineering 20, 315-324.

Beresnev, I.A. and Atkinson, G. M. (1997) Modeling finite-fault radiation from the $\omega^{n}$ spectrum. Bulletin of the Seismological Society of America 87, 67-84.

Beresnev, I.A. and Atkinson, G.M. (1998) FINSIM — a FORTRAN program for simulating stochastic acceleration time histories from finite faults. 69, 27-32.

Beresnev, I.A. and Atkinson, G.M. (1999) Generic finite-fault model for ground-motion prediction in Eastern North America. Bulletin of the Seismological Society of America 89, 608-625.

Beresnev, I.A. and Atkinson, G.M. (2001a) Subevent structure of large earthquakes-a ground motion perspective. Geophysical Research Letters 28, 53-56.

Beresnev, I. and Atkinson, G.M. (2001b) Correction to subevent structure of large earthquakes - a ground motion perspective. Geophysical Research Letters 28, 4663.

Boore, D.M. (2003) Simulation of ground motion using the stochastic method. Pure and Applied Geophysics 160, 635-676.

Castro, R.R., Rovelli, A., Cocco, M., Di Bona. M. and Pacor, F. (2001) Stochastic simulation of strong-motion records from the 26 September $1997\left(M_{\mathrm{w}} 6\right)$, Umbria-Marche (Central Italy) earthquake. Bulletin of the Seismological Society of America 91, 27-39.

Castro, R.R. and Ruíz-Cruz E. (2005) Stochastic modeling of the 30 September $1999 \mathrm{Mw}$ 7.5 earthquake, Oaxaca, Mexico. Bulletin of the Seismological Society of America 95(6), 2259-2271.

Duval, A.-M., Chatelain, J.-L., Guillier, B., and the SESAME WP02-Team (2004) Influence of experimental conditions on $\mathrm{H} / \mathrm{V}$ determination using ambient vibrations (noise). Proceedings of 11th ICSDEE \& 3rd ICEGE, Berkeley CA, 7-9 January 2004, Vol. 2, pp. $149-156$.

Erdik, M. and Durukal, E. (2003) Simulation modeling of strong ground motion. In Chen, W.F. and Scawthorn, C. (eds.), Earthquake Engineering Handbook. CRC Press, Boca Raton, Florida, 6, 16-67.

Field, E. and Jacob, K. (1993) The theoretical response of sedimentary layersto ambient seismic noise. Geophysical Research Letters 20, 2925-2928.

Geotechnical Engineering Division, (1985) Geotechnical Study in the metropolitan area of Thessaloniki. Report of the G.E.D. Department of Civil Engineering, Aristotle Univ. Thessaloniki, $136 \mathrm{p}$.

Hanks, T. C. (1982) $f_{\max }$. Bulletin of the Seismological Society of America 72, 1867-1879. 
Hartzell, S. (1978) Earthquake aftershocks as Green's functions. Geophysical Research Letters $5,1-4$.

Hatzidimitriou, P. (1993) Attenuation of coda waves in northern Greece. Pageoph 140, 6378.

Hatzidimitriou, P. (1995) S-wave attenuation in the crust in northern Greece. Bulletin of the Seismological Society of America 85, 1381-1387.

Hough, S.E., Martin, S., Bilham, R., and Atkinson, G.M. (2002) The 26 January 2001 M7.6 Bhuj, India earthquake: observed and predicted ground motions. Bulletin of the Seismological Society of America 92, 2061-2079.

Iglesias, A., Singh, S.K., Pacheco, J.F. and Ordaz, M. (2002) A source and wave propagation study of the Copalillo, Mexico, earthquake of 21 July 2000 ( $M_{w}$ 5.9): implications for seismic hazard in Mexico City from inslab earthquakes. Bulletin of the Seismological Society of America 92, 1060-1071.

IGME (1978) Geological Map: Thessaloniki Sheet (scale 1:50000), IGME edition.

IGME (1998) Engineering Geological Map: Thessaloniki Wider Area (scale 1:25000), IGME edition.

Irikura, K. (1983) Semi-empirical estimation of strong ground motions during large earthquakes. Bulletin of Disaster Prevention Research Institute, Kyoto University 33, 63-104.

Kamae, K., Irikura, K. and Pitarka, A. (1998) A technique for simulating strong ground motion using hybrid Green's function. Bulletin of the Seismological Society of America 88, 357-367.

Kappos, A., Stylianides, K. and Penelis, G. (1991) Analytical prediction of the response of structures to future earthquakes, European Earthquake Engineering 1, 10-21.

Konno, K. and Ohmachi, T. (1998) Ground-motion characteristics estimated from spectral ratio between horizontal and vertical components of microtremor. Bulletin of the Seismological Society of America 88(1), 228-241.

Kulhanek, O. and Meyer, K. (1983) Spectral study of the June 20, 1978 Thessaloniki earthquake. Publication Technical Chamber of Greece, Section of Central Macedonia. Papazachos and Carydis (eds), pp. 187-199.

Lachet, C. and Bard, P-Y. (1994) Numerical and theoretical investigations on the possibilities and limitations of the Nakamura's technique. Journal of Physics of the Earth 42, 377-397.

Lermo, L. and Chávez-García, J. (1994) Are microtremors useful in site response evaluation? Bulletin of the Seismological Society of America 84, 1350-1364.

Leventakis, G. (2003) Microzonation study of the city of Thessaloniki. PhD Thesis. Geological Dept., Aristotle Univ. Thes/niki, 84 p (in Greek with English abstract).

Motazedian, D. and Atkinson, G. M. (2005) Stochastic finite-fault modeling based on a dynamic corner frequency. Bulletin of the Seismological Society of America 95(3), 995-1010.

Nakamura, Y. (1989) A method for dynamic characteristics estimation of sub-surface using microtremors on the ground surface. Quick Report of Railway Technical Research Institute 30(1), 25-33 (in Japanese).

NEHRP (1994) Recommended provisions for seismic regulations for new buildings. Part 1. Provisions. FEMA 222 A, 1-32.

Ohta, Y., Kagami, H., Okada, S. and Ohashi, H. (1985) Seismic intensity and its application to engineering: a study in Japan. Proceedings NATO Advanced Study Institute on Strong Motion Seismology, June 10-21, 1985, MET Univ., Ankara, pp. 1-16.

Papageorgiou, A. (1988) On two characteristic frequencies of acceleration spectra: patch corner frequency and $f_{\max }$. Bulletin of the Seismological Soceity of America 78, 509-529.

Papageorgiou, A. and Aki, K. (1983) A specific barrier model of the quantitative description of inhomogeneous faulting and the prediction of strong ground motion I. Description of the model. Bulletin of the Seismological Society of America 73, 693-722. 
Papazachos, B. and Carydis, P. (eds.) (1983) The Thessaloniki, northern Greece, earthquake of June 20, 1978 and its seismic sequence. Publication Technical Chamber of Greece, Section of Central Macedonia, 451p.

Papazachos, B., Scordilis, E., Panagiotopoulos, D., Papazachos, C. and Karakaisis, G. (2004) Global relations between seismic fault parameters and moment magnitude of earthquakes. Bulletin of the Geology Society of Greece, Vol. XXXVI, Paper No. SE1_17.

Penelis, G., Stylianidis, K. and Stavrakakis, E. (1985) Statistical evaluation of the response of the buildings in the center of Thessaloniki to the earthquake of 20 June 1978, Proceedings of 12thRegional Seminar on Earthquake Engineering, Halkidiki, Greece.

Pitarka, A., Kamae, K., Somerville, P., Fukushima, Y., Uetake, T. and Irikura, K. (2000) Simulation of near-fault strongground motion using hybrid Green's function. Bulletin of the Seismological Society of America 90, 566-586.

Pitarka, A., Somerville, P. Fukushima, Y. and T. Uetake (2002) Ground-motion attenuation from the 1995 Kone earthquake based on simulations using the hybrid Green's function method. Bulletin of the Seismological Society of America 92(3), 1025-1031.

Pitarka, A., Somerville, P. Fukushima, Y. Uetake, T. and K. Irikura (2000) Simulation of near-fault strong ground motion using hybrid Green's function. Bulletin of the Seismological Society of America 90(3), 566-586.

Pitilakis, K., Anastasiadis, A. and Raptakis, D. (1992) Field and laboratory determination of dynamic properties of natural soil deposits. Proceedings of 10th World Conference Earthquake Engineering, Vol. 5, pp. 1275-1280.

Pulido, N. and Kubo, T. (2004) Near-fault strong motion complexity of the 2000 Tottori earthquake (Japan) from a broadband source asperity model. Tectonophysics 390, 177-192.

Pulido, N., Ojeda, A., Atakan, K. and Kubo, T. (2004) Strong ground motion estimation in the Marmara Sea region (Turkey) based on a scenario earthquake. Tectonophysics 391, 357-374.

Raptakis, D., Makra, K., Anastasiadis, A. and Pitilakis, K. (2004) Complex site effects in Thessaloniki (Greece). II. 2D SH modelling and engineering insights. Bulletin of Earthquake Engineering 2, 301-327.

RISK-UE Report, (2003) An advanced approach to earthquake risk scenarios, with applications to different European towns, EC Project No.: EVK4-CT-2000-00014.

Roumelioti, Z. and Beresnev, I. (2003) Stochastic finite-fault modeling of ground motions from the 1999 Chi-Chi, Taiwan, earthquake: application to rock and soil sites with implications for nonlinear site response. Bulletin of the Seismological Society of America 93(4), 1691-1702.

Roumelioti, Z., Kiratzi, A. and Theodulidis, N. (2004) Stochastic strong ground motion simulation of the 7 September 1999 Athens (Greece) earthquake. Bulletin of the Seismological Society of America 94, 1036-1052.

SESAME project (2005) European Project Final Report, http://SESAME-FP5.obs.ujf-grenoble.fr.

Singh, S.K., Bansal, B.K., Bhattacharya, S.N., Pacheco, J.F., Dattatrayam, R.S., Ordaz, M., Suresh, G., Kamal and Hough, S.E. (2003) Estimation of ground motion for Bhuj (26 January 2001; Mw 7.6) and for future earthquakes in India. Bulletin of the Seismological Society of America 93(1), 353-370.

Skarlatoudis, A., Papazachos, C., Margaris, B., Theodulidis, N., Papaioannou, Ch., Kalogeras, I., Scordilis, E. and Karakostas, V. (2003) Empirical peak ground-motion predictive relations for shallow earthquakes in Greece. Bulletin of the Seismological Society of America 93, 2591-2603.

Soufleris, Ch., Jackson, J., King, G., Spencer, C. and Scholz, C. (1982) The 1978 earthquake sequence near Thessaloniki (northern Greece). Geophysical Journal of the Royal Astronomical Society 68, 429-458. 
Soufleris, Ch. and Stewart, G. (1981) A source study of the Thessaloniki (northern Greece) 1978 earthquake sequence. Geophysical Journal of the Royal Astronomical Society 67, $343-358$

Stiros, S. and Drakos, A. (2000) Geodetic constraints on the fault pattern of the 1978 Thessaloniki (northern Greece) earthquake (Ms=6.4), Geophys. J. Int., 143, 679-688.

Theodulidis, N. and Bard, P-Y. (1998) Dependence of $f_{\max }$ on site geology: a preliminary study of Greek strong-motion data. Proceedings of 11th European Conferance Earthquake Engineering, Abstr. Vol. 562 \& CD ROM.

Theodulidis, N., Cultrera, G. Tento, A. Faeh, D. Atakan, K., Bard, P.-Y., Panou, A. and the SESAME-Team, (2004) Empirical evaluation of the horizontal-to-vertical spectral ratio technique: results from the SESAME project. Proceedings of the 13th World Conference on Earthquake Engineering, Vancouver, August 2004, Paper No. 2323.

Theodulidis, N. and Papazachos, B. (1994) Dependence of strong ground motion on magnitude-distance, site geology and macroseismic intensity for shallow earthquakes in Greece: II, Horizontal pseudovelocity. Soil Dynamics and Earthquake Engineering 13, 317-343.

Tranos, M., Papadimitriou, E. and Kilias, A. (2003) Thessaloniki-Gerakarou fault zone (TGFZ): the extension of the 1978 Thessaloniki earthquake fault (Northern Greece) and seismic hazard assessment. Journal of Struct. Geol., 25, 2109-2123.

Triantafyllidis, P., Suhadolc, P., Hatzidimitriou, P., Anastasiadis, A. and Theodulidis, N. (2004) Part I: theoretical site response estimation for microzoning purposes. Pageoph, $161,1185-1203$.

Tsotsos, S. and Pitilakis, K. (1986) Geotechnical properties of Thessaloniki soil formations, Proceedings of 1st Hellenic Conference, on Soil Mechanics, Vol. I, pp. 115-118 (in Greek).

Tsotsos, S. and Zissis-Tegos, G. (1986) Seismic microzonation study of Thessaloniki area and comparison with the observed damage distribution during the June, 1978 earthquake. Proceedings of 8th European Conference on Earthquake Engineering, Lisbon, Portugal, Sept. 7-12, Vol. 5.1, pp. 25-32.

Wells, D. and Coppersmith, K. (1994) New empirical relationships among magnitude, ruptutre length, rupture width, rupture area and surface displacement. Bulletin of the Seismological Society of America 84, 974-1002.

Zar, J.R. (1984) Biostatistical Analysis, Book Edited by Prentice-Hall International, Inc., $718 \mathrm{p}$. 